\title{
Prognostic significance of mRNA expression of CASPs in gastric cancer
}

\author{
ZIXIANG WANG $^{1 *}$, FUBIAO NI $^{2 *}$, FANGYI YU $^{1}$, ZHONGHUI CUI $^{1}$, XIANDONG ZHU ${ }^{2}$ and JICAI CHEN ${ }^{3}$ \\ ${ }^{1}$ First School of Clinical Medicine, Wenzhou Medical University; Departments of ${ }^{2}$ Hepatobiliary Surgery and \\ ${ }^{3}$ General Surgery, The First Affiliated Hospital of Wenzhou Medical University, Wenzhou, Zhejiang 325000, P.R. China
}

Received March 10, 2019; Accepted July 16, 2019

DOI: $10.3892 / \mathrm{ol} .2019 .10816$

\begin{abstract}
Current studies suggest that the cysteinyl aspartate specific proteinase (caspase/CASP) family may be closely associated with apoptosis. Scientists have suggested that caspases may be a key to the development of more effective anti-cancer therapies. However, the prognostic value of CASP expression in gastric cancer (GC) remains unclear. Using a Kaplan-Meier plotter online database, the predictive prognostic significance of the expression of 12 CASPs genes (CASP1, CASP2, CASP3, CASP4, CASP5, CASP6, CASP7, CASP8, CASP9, CASP10, CASP12 and CASP14) to overall survival (OS) in different clinicopathological features, including Lauren classification, pathological stages, therapies employed and differentiation in gastric cancer patients was explored. The present study revealed that higher CASP1, 2, 3, 4, 5, 6, 7 and 8 mRNA expression was associated with better OS, whereas higher
\end{abstract}

Correspondence to: Dr Jicai Chen, Department of General Surgery, The First Affiliated Hospital of Wenzhou Medical University, 5 Fuxuexiang Road, Wenzhou, Zhejiang 325000, P.R. China

E-mail: cjc60321@163.com

*Contributed equally

Abbreviations: 5-FU, 5-Fluorouracil; Apaf1, apoptotic peptidase activating factor 1; Bcl-2, B-cell lymphoma 2; Bid, BH3 interacting domain death agonist; caspase, cysteinyl aspartate specific proteinase; CASP1, caspase 1; CASP2, caspase 2; CASP3, caspase 3; CASP4, caspase 4; CASP5, caspase 5; CASP6, caspase 6; CASP7, caspase 7; CASP8, caspase 8; CASP9, caspase 9; CASP10, caspase 10; CASP12, caspase 12; CASP14, caspase 14; CI, Confidence intervals; CRADD, CASP2 and RIPK1 domain containing adaptor with death domain; ER, endoplasmic reticulum; FADD, Fas associated via death domain; GC, Gastric cancer; HER2, Human epidermal growth factor receptor-2; HGU133, Human Genome U133; HR, Hazard ratio; KM plotter, Kaplan-Meier plotter; MAPK, mitogen-activated protein kinase; OS, Overall survival; P, Probability; P-caspase 9, phosphorylated caspase 9; TRADD, TNFRSF1A associated via death domain

Key words: Caspase, prognosis, gastric cancer, Kaplan Meier plotter expression of CASP9, 10, 12 and 14 showed an unfavorable OS in all GC patients. Moreover, CASP1 to 8 were all associated with favorable OS in intestinal type and diffuse type classified by Lauren classification. Therefore, the results of the present study suggested that the CASP family may function as new prognostic indicators in GC and may be helpful in making treatment decisions.

\section{Introduction}

Gastric cancer (GC) is the fourth most commonly diagnosed cancer and the second leading cause of cancer-associated mortality worldwide (1). Despite its early detection and current improvements in surgery with perioperative chemotherapy, GC, with a median overall survival (OS) of 12 months, remains difficult to treat and form a prognosis due to the lack of specific symptoms during the early stages of disease and metastasis $(1,2)$. Recurrence is likely to occur during the follow-up period as effective therapies are unavailable. At present, only the pathological and clinical stages of disease are accepted as conventional criteria to aid the treatment selection process. To improve the OS of patients with this disease, the identification of novel prognostic markers and potential therapeutic targets is urgently required.

Apoptosis is a process of programmed cell death; defects in apoptosis can lead to the development of cancer or autoimmune disease. It has been reported that carcinogenesis could be suppressed via apoptotic pathways through inducible proteins, including inhibitors of apoptosis or FLICE-like inhibitory protein (3). The cysteinyl aspartate specific proteinase (caspase/CASP) family of proteins can also induce apoptosis. CASPs are a group of proteases with similar structures in the cytoplasm, comprising small and large catalytic subunits plus a prodomain. Their active sites contain cysteine residues, which specifically cleave the peptide bonds of aspartic acid residues of target proteins (4). CASPs are involved in cell growth and differentiation, as well as the regulation of eukaryotic apoptosis $(4,5)$. According to the homology of its protease sequence, CASPs can be divided into three subfamilies: CASP1 subfamily, including CASPs 1, 4, 5, 11, 12 and 14, which serve as inflammatory proteases; the CASP2 subfamily, including CASPs 2 and 9, which are upstream CASPs that process proinflammatory cytokines or induce apoptosis, and the CASP3 subfamily, which includes the effector proteases, 
A

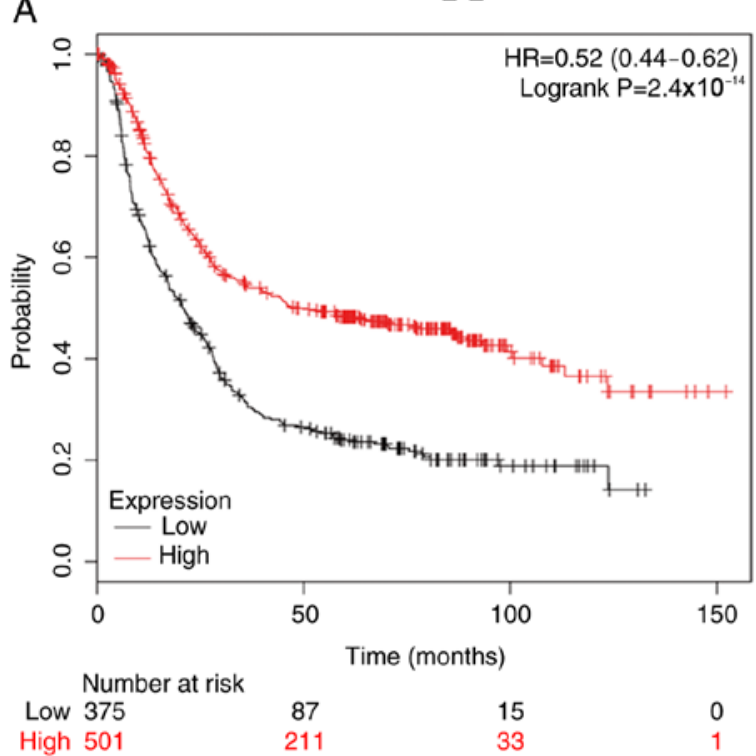

C

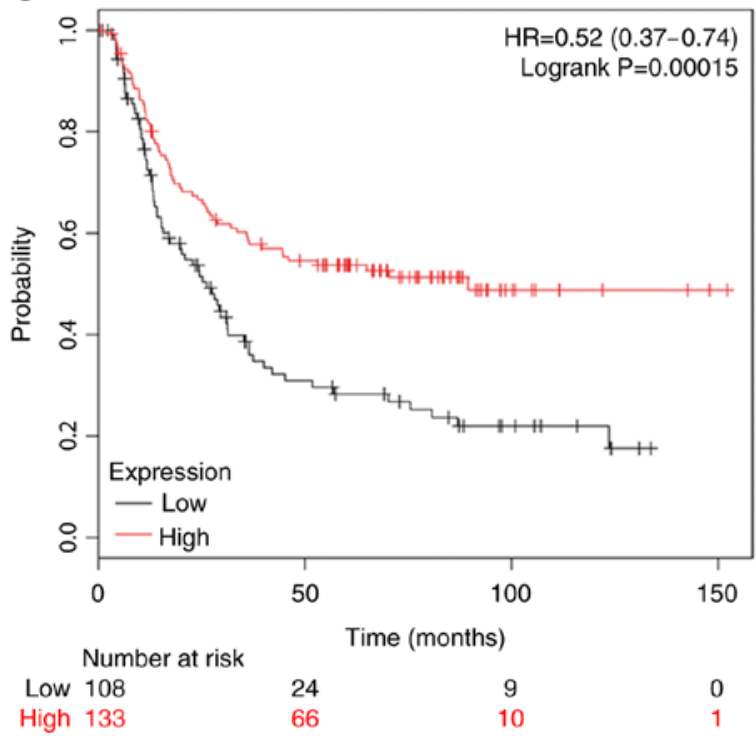

B

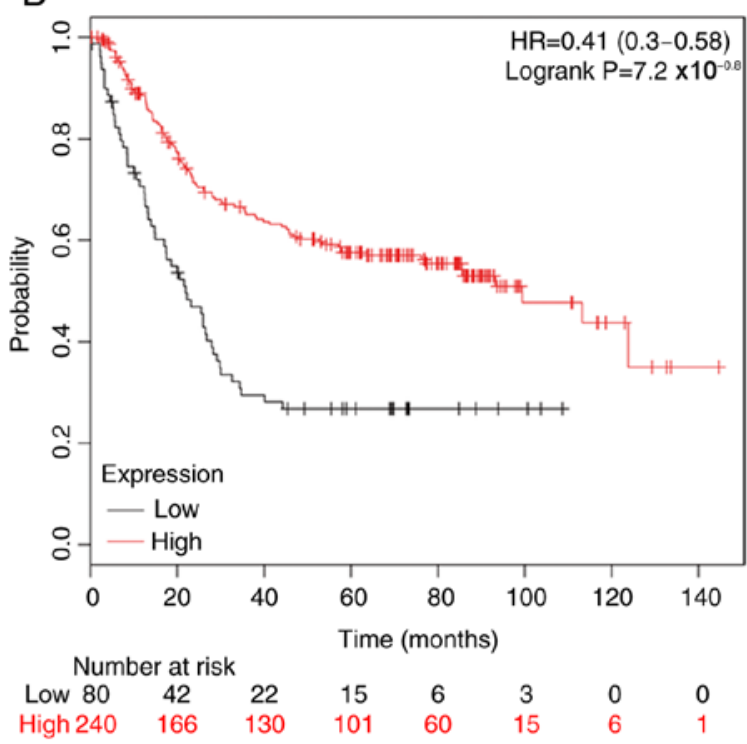

D

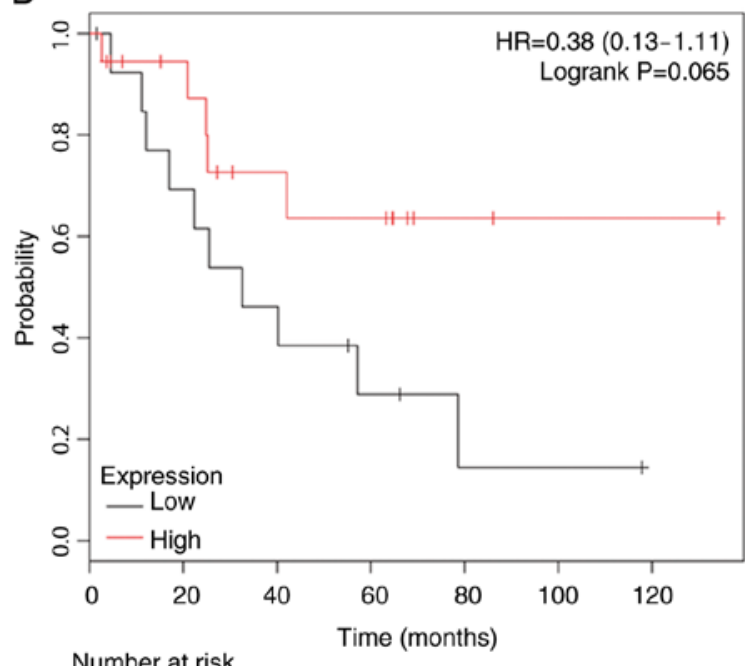

$\begin{array}{ccccccc}\text { Low } 14 & 9 & 6 & 3 & 1 & 1 & 0 \\ \text { High } 18 & 13 & 8 & 7 & 2 & 1 & 1\end{array}$

Figure 1. The prognostic significance of CASP1 expression in GC. The prognostic value of CASP1 expression in www.kmplot.com. Affymetrix ID for CASP1: 211368 _s_at. OS curves were plotted for $(A)$ all patients $(n=876),(B)$ patients with intestinal cancer $(n=320)$, $(C)$ patients with diffuse cancer $(n=241)$ and (D) patients with mixed cancer $(n=32)$. GC, gastric cancer; OS, overall survival; CASP1, caspase 1; HR, hazard ratio.

CASPs 3, 6, 7, 8 and 10 (6,7). The CASP family-mediated signaling pathway involves a cascade of enzymatic reactions; each component forms a complex network structure. It has been suggested that CASPs may be key for the development of more effective anticancer therapies (4). The vital role of these proteins in medicine has been reported and their substrates may be considered as anticancer drug targets as chemotherapeutic agents induce the death of malignant cells by acting upstream of CASPs (5); however, the prognostic value of the CASP family of proteins in GC has not yet been determined.

Based on highly specialized complexes in response to various proinflammatory and proapoptotic signals, the CASP protein family may be stimulated in the intrinsic and extrinsic pathway. For the former pathway, with chemical stimuli and a lack of growth factors or radiation, increases in the membrane permeability of mitochondria and the transport of cytochrome $c$ from its interspace into the cytosol lead to the formation of the apoptosome, which recruits apoptotic peptidase activating factor 1 (Apaf 1), proCASP-9 and ATP $(4,8)$. In addition, cellular damage signaling via p53 or other sensors to antagonize the Bcl-2 family of proteins results in increased permeabilization of the mitochondria (5). On the contrary, in the extrinsic pathway, tumor necrosis factor (TNF)- $\alpha$ or Fas ligand engages their own cell membrane receptor, the TNF receptor (TNFR) or Fas, causing the oligomerization of the TNFR superfamily member 1A-associated death domain (TRADD) or Fas-associated death domain (FADD), respectively. Subsequently, a death-inducing signaling complex forms, which associates with CASPs to induce certain effects $(4,9)$.

The present study performed a comprehensive analysis using the Kaplan-Meier plotter (KM plotter) tool to determine whether the expression of CASPs genes is associated with the 

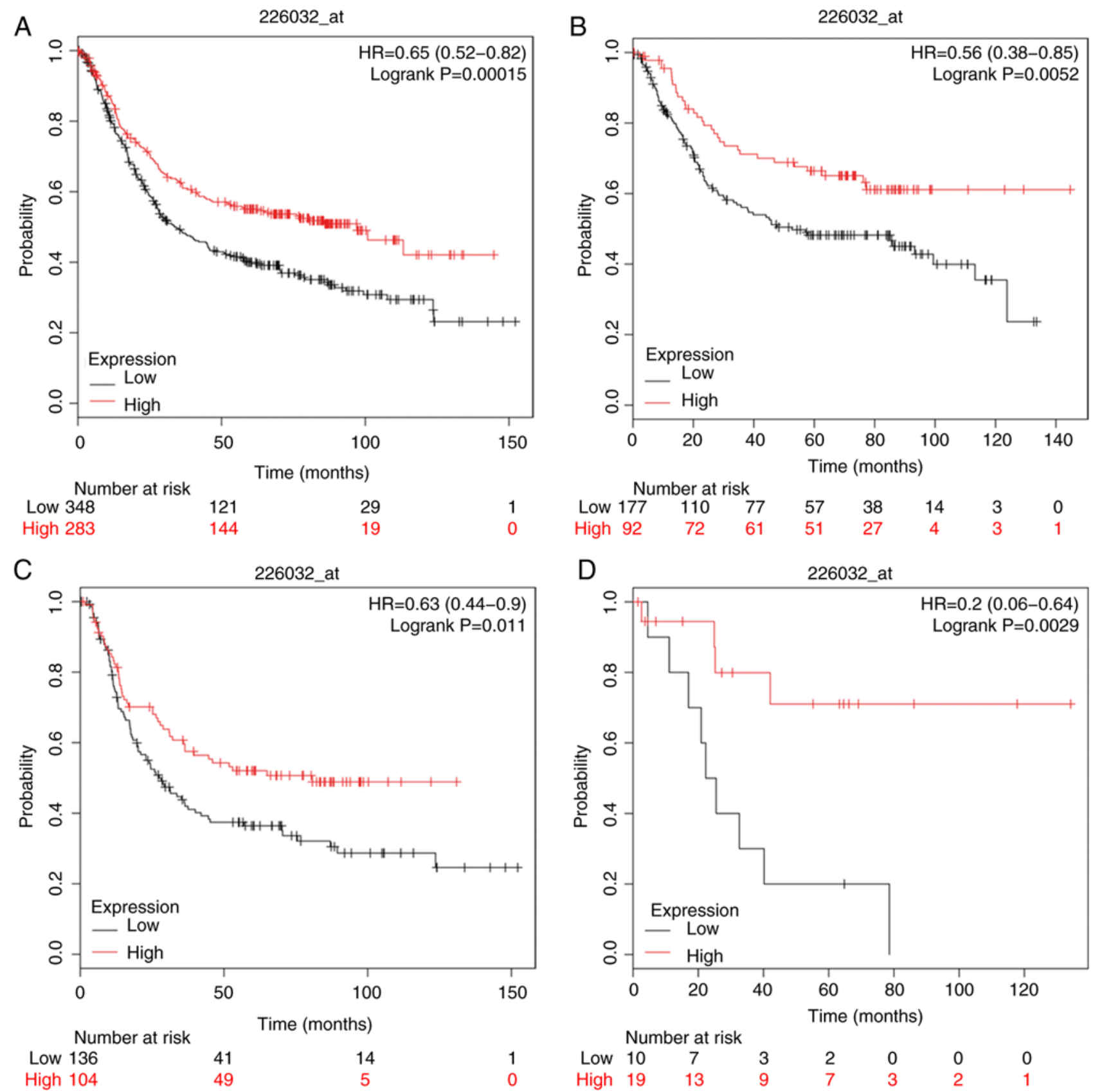

Figure 2. The prognostic significance of CASP2 expression in GC. The prognostic value of CASP2 expression in www.kmplot.com. Affymetrix ID for CASP2: 226032 at. OS curves were plotted for $(A)$ all patients $(n=631),(B)$ patients with intestinal cancer $(n=269)$, (C) patients with diffuse cancer ( $=240)$ and (D) patients with mixed cancer $(n=29)$. GC, gastric cancer; OS, overall survival; CASP2, caspase 2; HR, hazard ratio.

prognosis of GC and the various clinicopathological features of patients with this disease. The results suggested that CASP mRNA expression levels may be crucial prognostic biomarkers and that anticancer drug targeting and the regulation of gene expression may improve the therapeutic effects of treatment.

\section{Materials and methods}

Survival analysis. The association between the mRNA expression profile of members of the CASP protein family and the OS of patients with GC was analyzed with KM plotter (http://kmplot.com/analysis/); expression profiles (dataset numbers: GSE14210, GSE15459, GSE22377, GSE29272 and GSE62254) were downloaded from the Gene Expression
Omnibus and The Cancer Genome Atlas (10,11), with 876 GC patient samples divided into high- and low-expression groups based on the median expression levels of each gene. The Affymetrix GeneChip platform provided probes for each gene (12). Only samples measured on Human Genome U133 plus 2.0 arrays were included in the analysis. Information of the databases were validated by literature searches for various prognostic markers in GC in PubMed for the prediction of OS using univariate and multivariate Cox proportional hazards regression analyses (10).

Determination of CASP gene prognostic values. The 12 selected CASP genes comprising the array were: CASP1, CASP2, CASP3, CASP4, CASP5, CASP6, CASP7, CASP8, 
A

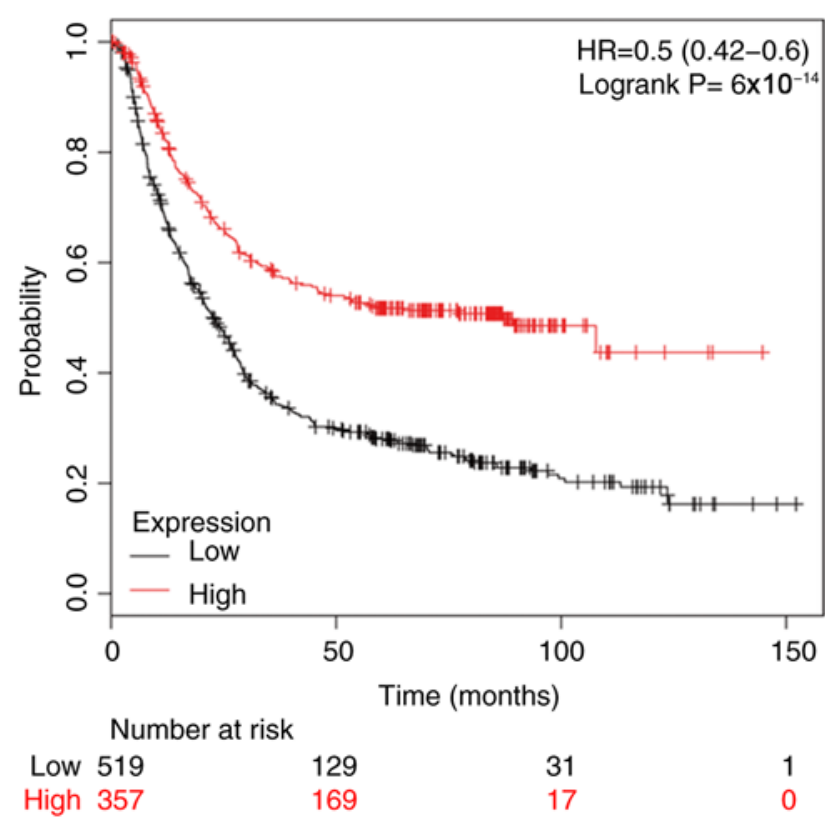

C

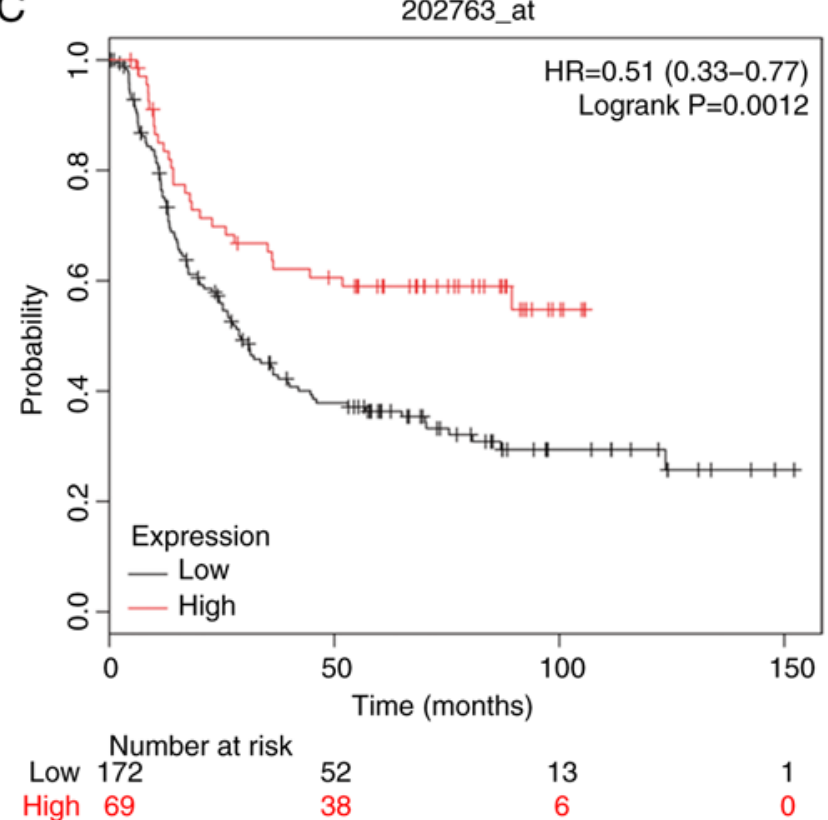

B

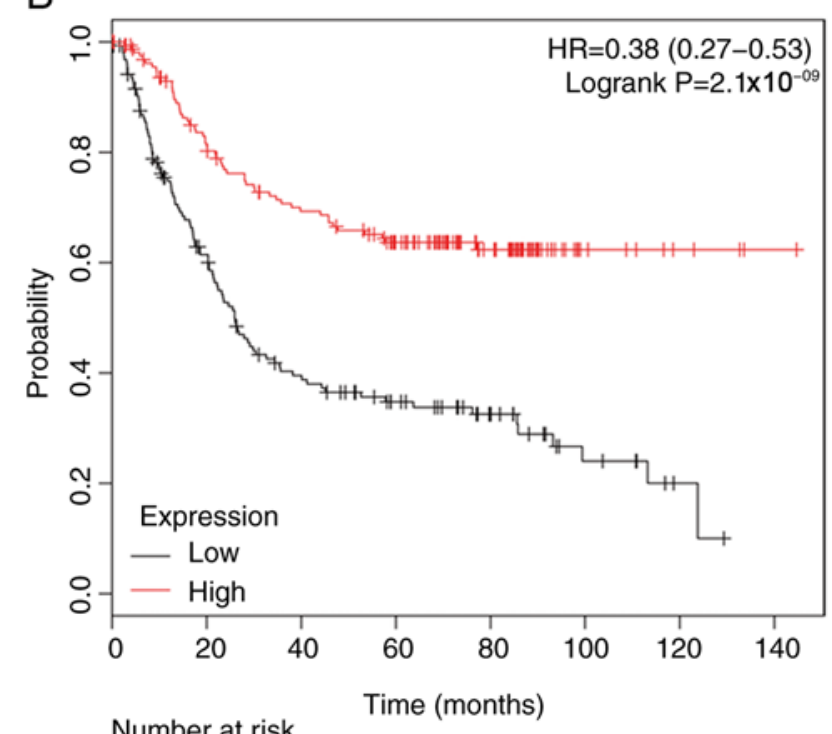

$\begin{array}{cccccccc}\text { Low } 158 & 86 & 52 & 37 & 22 & 9 & 2 & 0 \\ \text { High } 162 & 122 & 100 & 79 & 44 & 9 & 4 & 1\end{array}$

D

202763_at

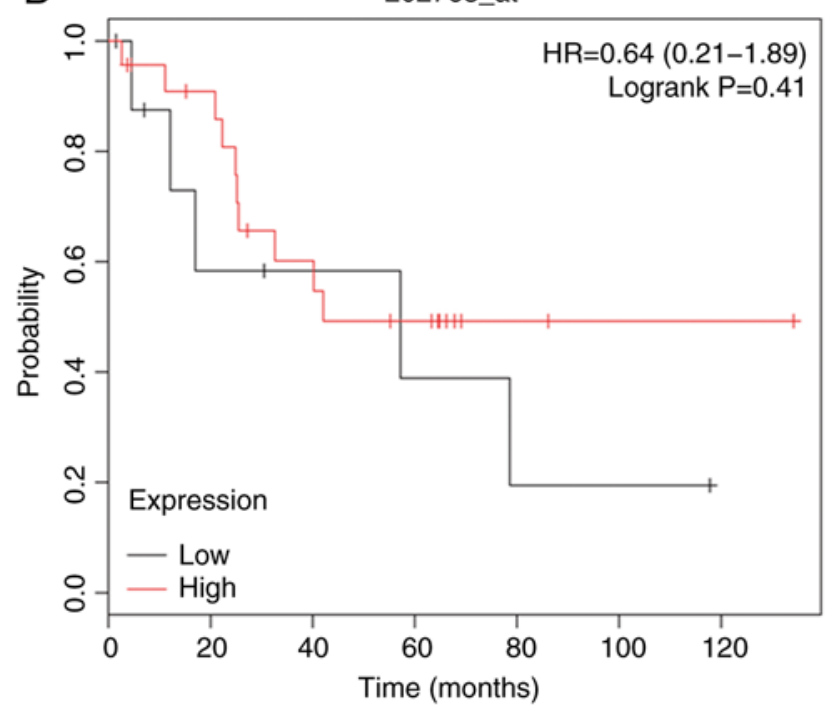

Number at risk

$\begin{array}{lccccccc}\text { Low } & 9 & 4 & 3 & 2 & 1 & 1 & 0 \\ \text { High } & 23 & 18 & 11 & 8 & 2 & 1 & 1\end{array}$

Figure 3. The prognostic significance of CASP3 expression in GC. The prognostic value of CASP3 expression in www.kmplot.com. Affymetrix ID for CASP3: 202763_at. OS curves were plotted for (A) all patients ( $n=876)$, (B) patients with intestinal cancer $(n=320)$, (C) patients with diffuse cancer ( $\mathrm{n}=241)$ and (D) patients with mixed cancer ( $\mathrm{n}=32$ ). GC, gastric cancer; OS, overall survival; CASP3, caspase 3; HR, hazard ratio.

CASP9, CASP10, CASP12 and CASP14, which serve vital roles in the caspase pathway. The prognostic value of each caspase ligand was evaluated via K-M survival plots, using GC tumor data, or by using several clinical GC criteria and classifications, including the Lauren classification (intestinal type, diffuse type and mixed type) and clinicopathological features [mortality, human epidermal growth factor receptor-2 (HER2) expression status, pathological stages, sex, treatment strategy and differentiation degree]. The treatment strategies were sorted into the surgery alone group, fluorouracil (5-FU)-based adjuvant group and other adjuvant group; for pathological stages, patients were classified into four stages.
The number-at-risk was also determined from analysis. Hazard ratios (HRs) with 95\% confidence interval (95\% CI) and log-rank $\mathrm{P}$-values were calculated. $\mathrm{P}<0.05$ was considered to indicate a statistically significant difference.

\section{Results}

Association between OS of all patients based on mRNA expression and Lauren classification. The data of the 12 CASP genes present in the KM plotter database were employed for the analysis of OS. The OS for 876 patients with GC was investigated in association with 9 genes (CASP1, CASP3, CASP4, CASP5, 
A

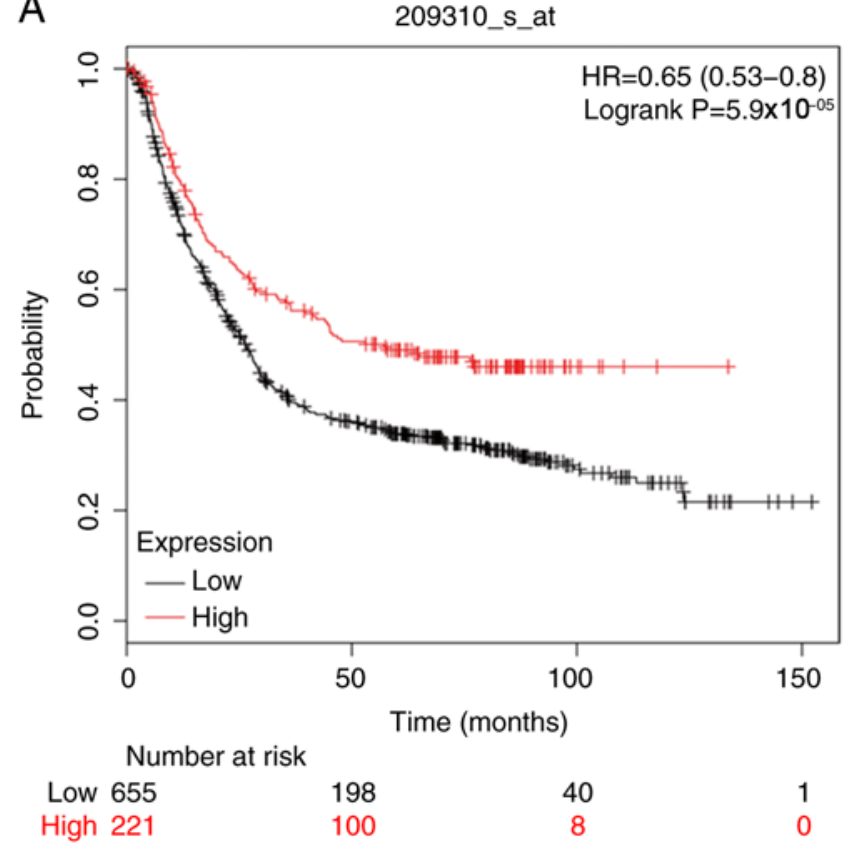

C

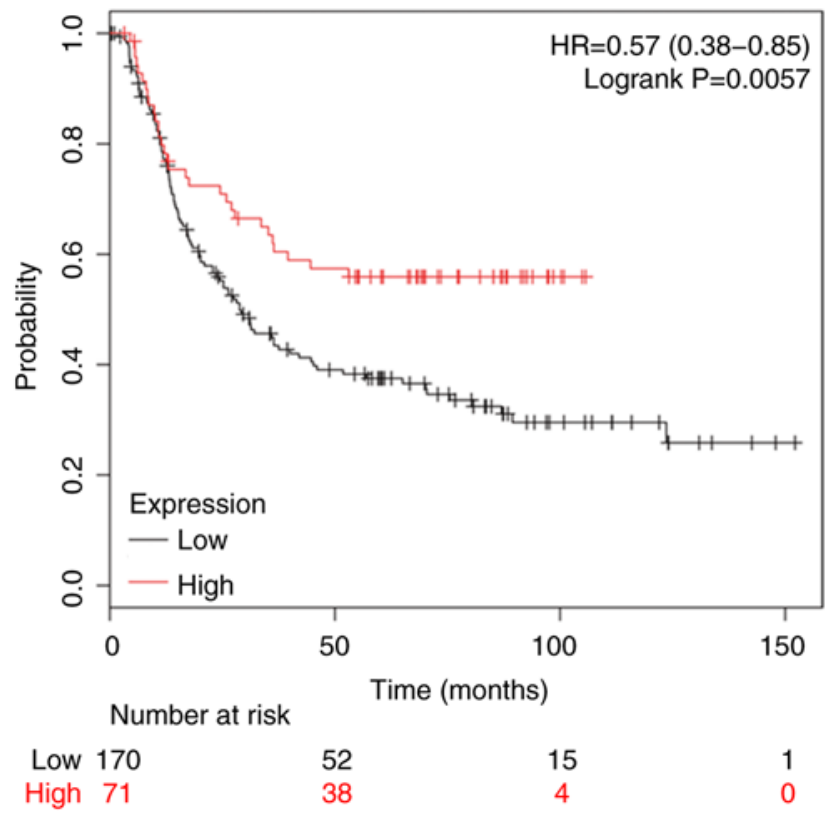

B

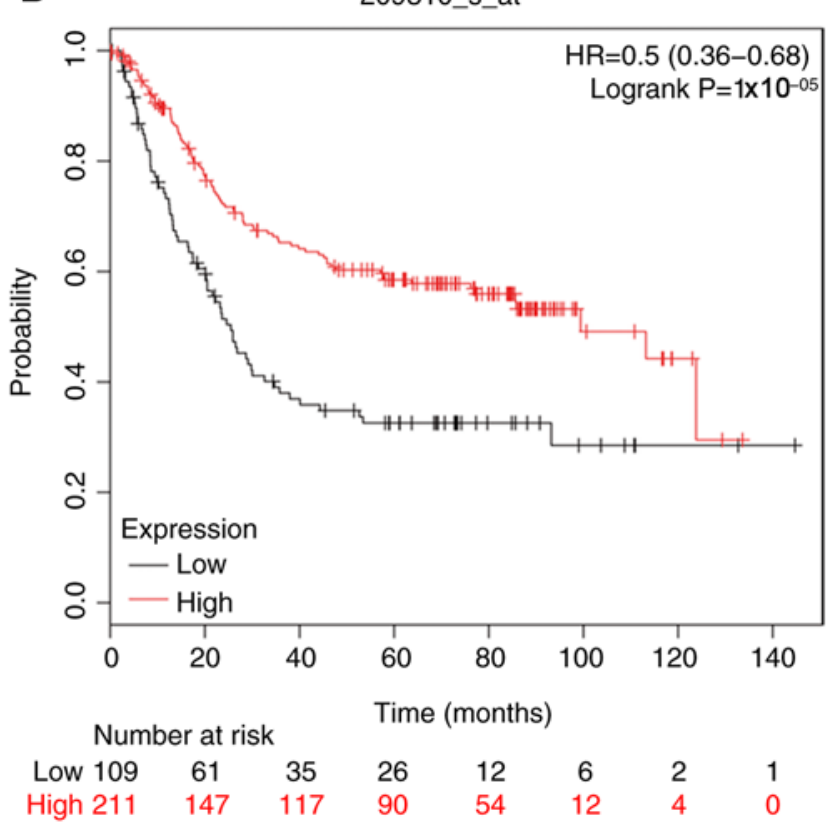

$\mathrm{D}$

209310_s_at

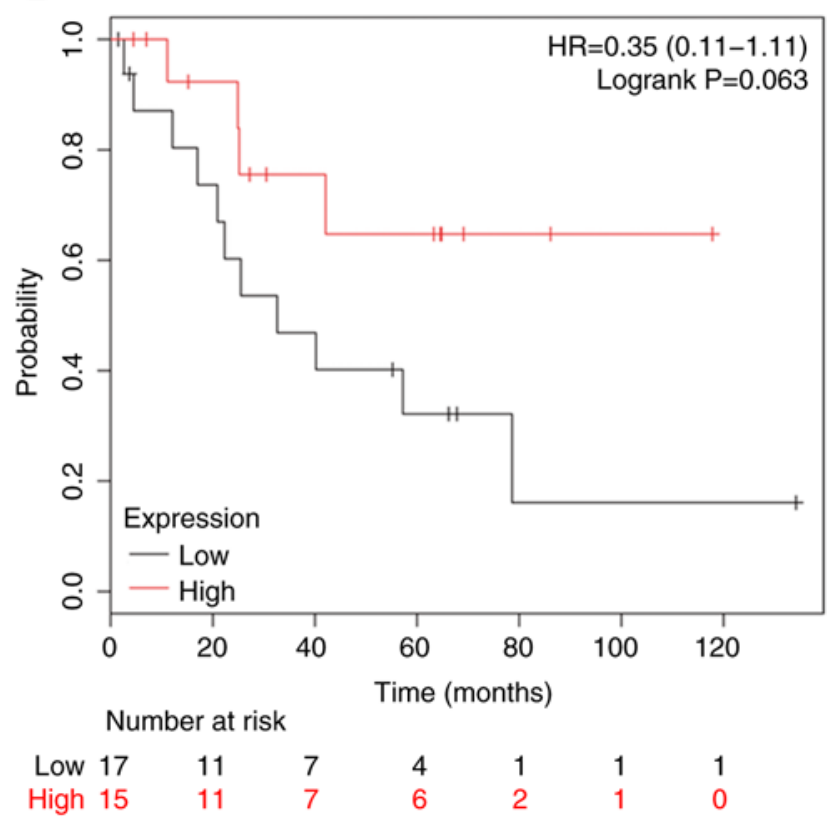

Figure 4. The prognostic significance of CASP4 expression in GC. The prognostic value of CASP4 expression in www.kmplot.com. Affymetrix ID for CASP4: 209310_s_at. OS curves were plotted for (A) all patients $(n=876)$, (B) patients with intestinal cancer $(n=320)$, (C) patients with diffuse cancer $(n=241)$ and (D) patients with mixed cancer ( $\mathrm{n}=32$ ). $\mathrm{GC}$, gastric cancer; OS, overall survival; CASP4, caspase 4; HR, hazard ratio.

CASP6, CASP7, CASP8, CASP9 and CASP10). Separate curves were plotted to determine the association between OS and the Lauren classification criteria, including intestinal type $(n=320)$, diffuse type $(\mathrm{n}=241)$ and mixed type $(\mathrm{n}=32)$. Investigations into CASP2, CASP12 and CASP14 were conducted with 631 patient samples analyzed on Human Genome U133 plus 2.0 arrays which could only be included when using the selected probes, containing 269, 240 and 29 samples of intestinal, diffuse and mixed types respectively.

The prognostic value of CASP1 was initially assessed in the database (Affymetrix ID: 211368_s_at). As presented in Fig. 1, increased mRNA expression of CASP1 was associated with better OS in all patients with GC $[\mathrm{HR}=0.52(0.44-0.62)$, $\left.\mathrm{P}=2.4 \times 10^{-14}\right]$; improved $\mathrm{OS}$ was related to intestinal type $\left[\mathrm{HR}=0.41(0.3-0.58), \mathrm{P}=7.2 \times 10^{-8}\right]$ and diffuse type $[\mathrm{HR}=0.52$ (0.37-0.74), $\left.\mathrm{P}=1.5 \times 10^{-4}\right]$.

For CASP2 (Affymetrix ID: 226032_at), increased mRNA expression was positively associated with $\mathrm{OS}$ in all patients with $\mathrm{GC}$ [HR=0.65 (0.52-0.82), $\mathrm{P}=1.5 \times 10^{-4}$; Fig. 2], corresponding to the outcome of the intestinal, diffuse and mixed types in $\mathrm{GC}\left[\mathrm{HR}=0.56(0.38-0.85), \mathrm{P}=5.3 \times 10^{-3} ; \mathrm{HR}=0.63(0.44-0.9)\right.$, $\mathrm{P}=0.011 ; \mathrm{HR}=0.2(0.06-0.64), \mathrm{P}=2.9 \times 10^{-3}$; respectively].

The prognostic significance of CASP3, CASP4, CASP5, CASP6, CASP7 and CASP8 expression was investigated 
A

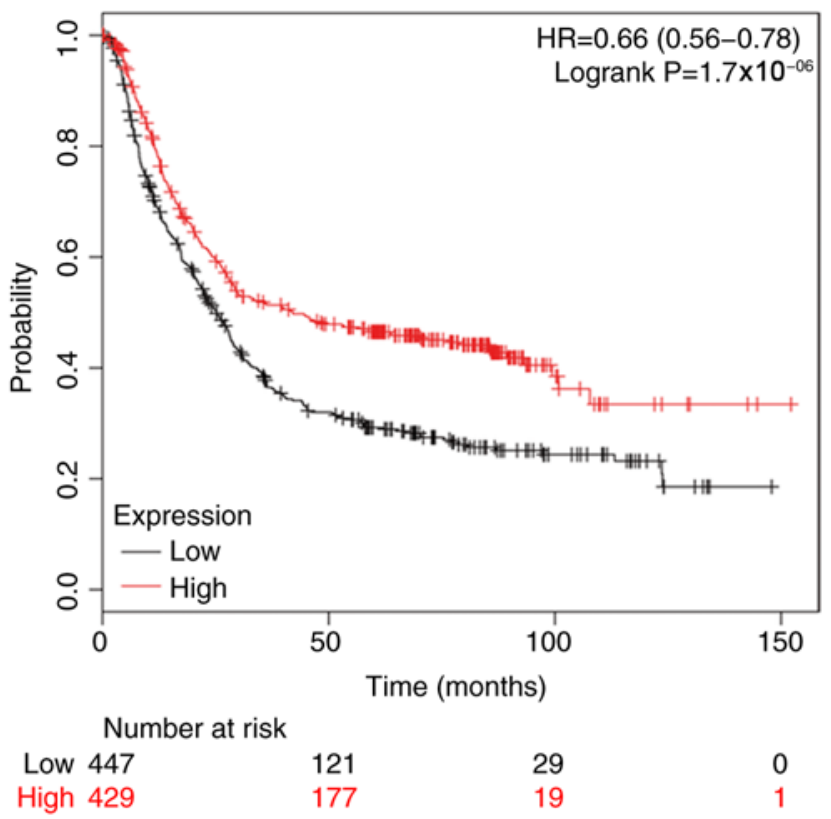

C

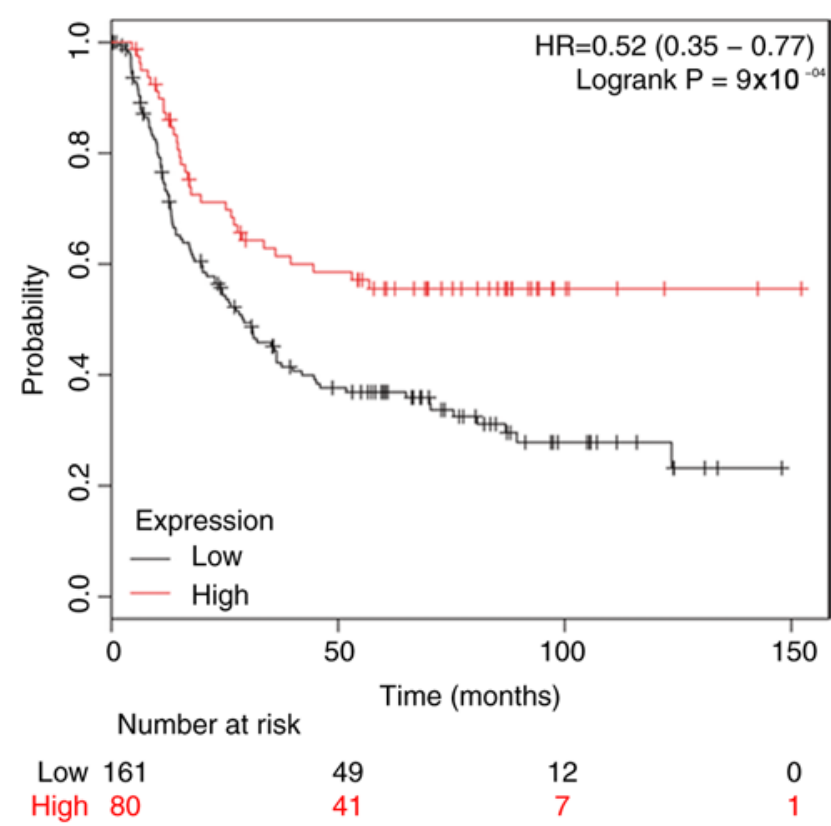

B

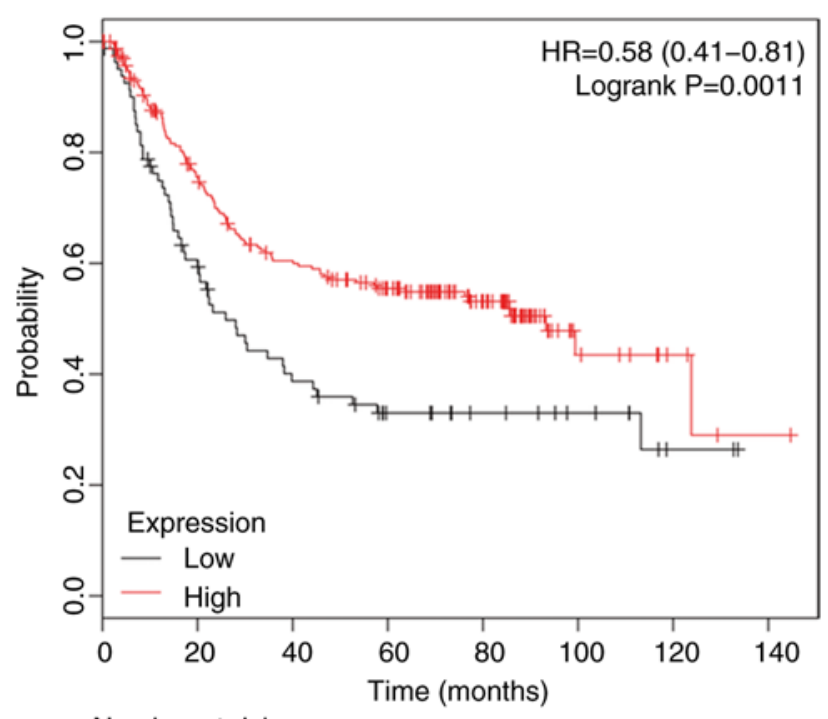

Number at risk

$\begin{array}{cccccccc}\text { Low 82 } & 46 & 28 & 17 & 12 & 8 & 2 & 0 \\ \text { High 238 } & 162 & 124 & 99 & 54 & 10 & 4 & 1\end{array}$

D

207500_at

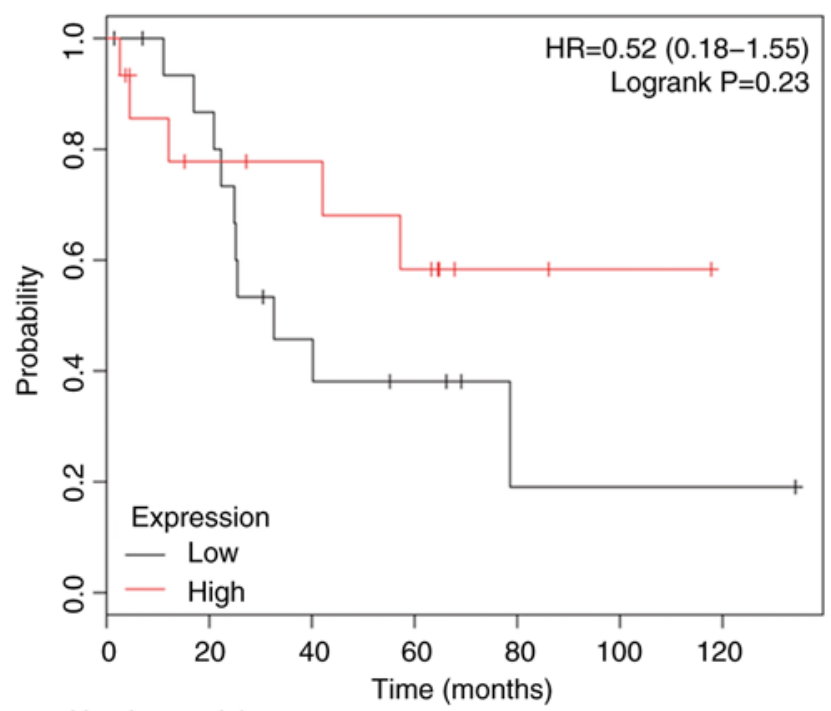

Number at risk

$\begin{array}{lclllll}\text { Low } 17 & 13 & 6 & 4 & 1 & 1 & 1\end{array}$

Figure 5. The prognostic significance of CASP5 expression in GC. The prognostic value of CASP5 expression in www.kmplot.com. Affymetrix ID for CASP5: 207500_at. OS curves were plotted for (A) all patients $(n=876)$, (B) patients with intestinal cancer $(n=320)$, (C) patients with diffuse cancer ( $\mathrm{n}=241)$ and (D) patients with mixed cancer ( $\mathrm{n}=32$ ). GC, gastric cancer; OS, overall survival; CASP5, caspase 5; HR, hazard ratio.

using the corresponding Affymetrix databases: 202763_at, 209310_s_at, 207500_at, 209790_s_at, 207181_s_at and 213373_s_at. The mRNA expression levels of the aforementioned CASPs were associated with favorable OS in patients with GC $\left[\mathrm{HR}=0.5(0.42-0.6), \mathrm{P}=6 \times 10^{-14} ; \mathrm{HR}=0.65(0.53-0.8)\right.$, $\mathrm{P}=5.9 \times 10^{-5} ; \mathrm{HR}=0.66(0.56-0.78), \mathrm{P}=1.7 \times 10^{-6} ; \mathrm{HR}=0.68$ (0.57-0.81), $\mathrm{P}=1.2 \times 10^{-5} ; \mathrm{HR}=0.44(0.36-0.54), \mathrm{P}=2.2 \times 10^{-16}$ and $\mathrm{HR}=0.63(0.53-0.74), \mathrm{P}=5.7 \times 10^{-8}$; respectively], as well as patients of intestinal and diffuse GC types, but not mixed type GC (Figs. 3-8).

As presented in Figs. 9-11, increased expression of CASP9 (Affymetrix ID: 203984_s_at) and CASP12 (Affymetrix
ID: 1564736_a_at) was associated with poor OS in patients with GC $\left[\mathrm{HR}=1.21\right.$ (1-1.46), $\mathrm{P}=4.8 \times 10^{-2} ; \mathrm{HR}=1.39$ (1.12-1.72), $\left.\mathrm{P}=3 \times 10^{-3}\right]$; CASP12 was linked to diffuse type $\mathrm{GC}[\mathrm{HR}=1.66$ (1.15-2.38), $\mathrm{P}=5.7 \times 10^{-3}$ ]. Unexpectedly, diffuse type patients with high CASP9 mRNA expression levels exhibited improved OS $\left[\mathrm{HR}=0.69(0.48-0.98), \mathrm{P}=3.7 \times 10^{-3}\right]$. Of note, intestinal and mixed GC types were not associated with OS for either gene.

Furthermore, the prognostic value of CASP10 and CASP14 was investigated using Affymetrix databases (210955_at and 231722_at, respectively). Upregulated CASP10 and CASP14 mRNA expression was significantly associated with poor OS in patients with $\mathrm{GC}\left[\mathrm{HR}=1.4(1.18-1.67), \mathrm{P}=1.1 \times 10^{-4} ; \mathrm{HR}=1.56\right.$ 
A

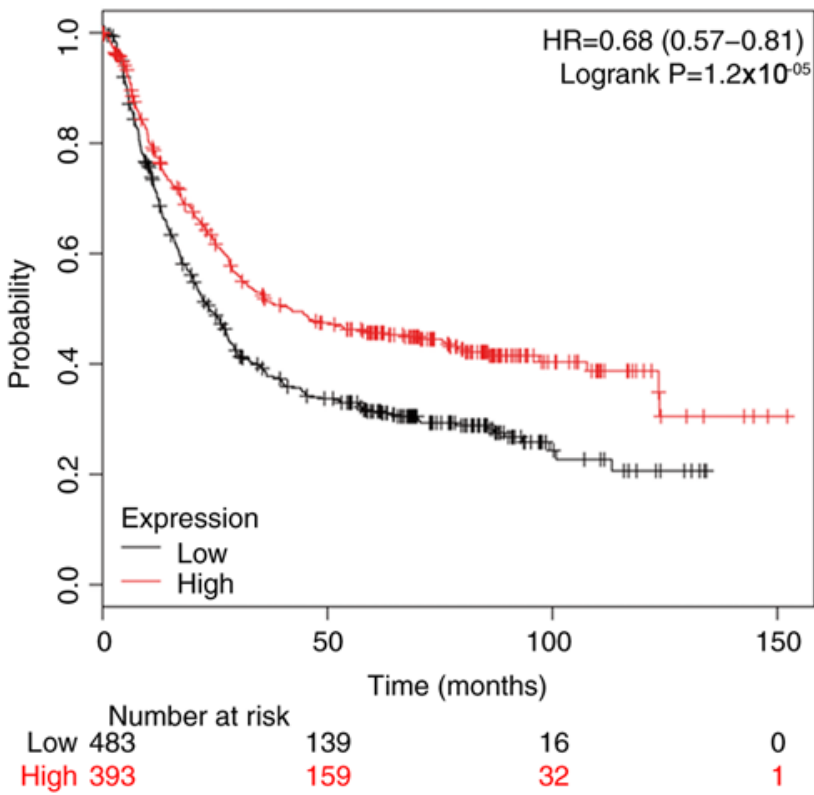

C

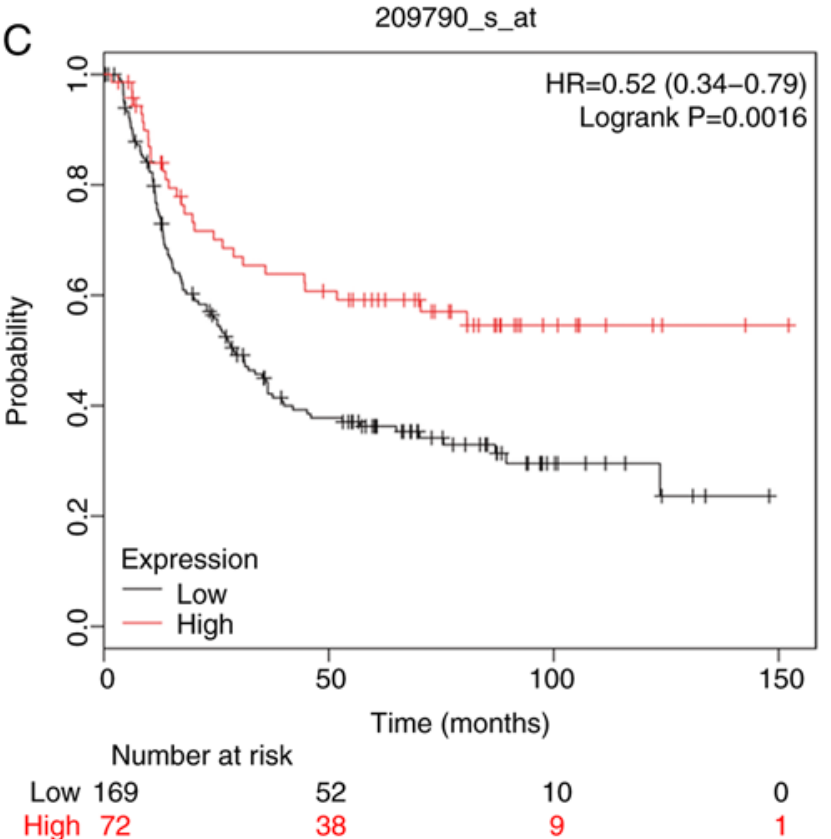

B
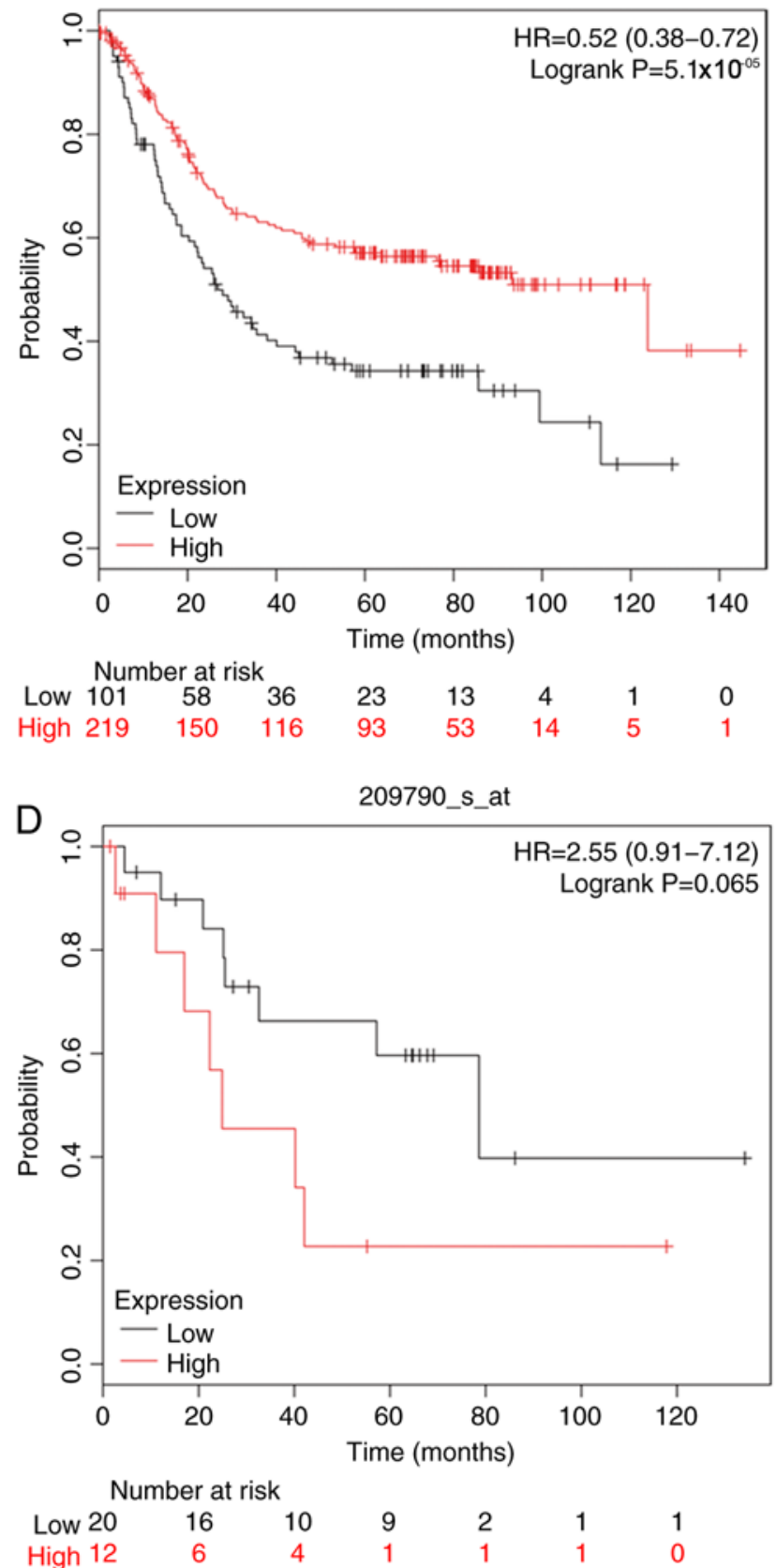

Figure 6. The prognostic significance of CASP6 expression in GC. The prognostic value of CASP6 expression in www.kmplot.com. Affymetrix ID for CASP6: 209790_s_at. OS curves were plotted for (A) all patients $(\mathrm{n}=876)$, (B) patients with intestinal cancer $(\mathrm{n}=320)$, (C) patients with diffuse cancer (n=241) and (D) patients with mixed cancer $(n=32)$. GC, gastric cancer; OS, overall survival; CASP6, caspase 6; HR, hazard ratio.

(1.25-1.93), $\left.\mathrm{P}=5.8 \times 10^{-5}\right]$; intestinal type $\mathrm{GC}$ was also related to poor OS $\left[\mathrm{HR}=1.56(1.13-2.13), \mathrm{P}=5.9 \times 10^{-3} ; \mathrm{HR}=2.02(1.4-2.91)\right.$, $\mathrm{P}=1.3 \times 10^{-4}$ ] (Figs. 10 and 12). In addition, analysis of mixed type $\mathrm{GC}$ indicated that the expression of CASP10 and CASP14 above or below the median level could not be applied to distinguish patients of distinct prognostic groups.

Association between OS based on MRNA expression and clinicopathological features. To further examine the association between the expression of individual CASP genes and other clinicopathological parameters, the links between OS and mortality (Table I), pathological grade (Table II), HER2 expression status (Table III), treatment strategy (Table IV), sex
(Table V) and differentiation degree (Table VI), were determined.

The association between the expression levels of CASPs and the 50-month mortality rate was investigated in patients with GC. In Table I, high expression levels of CASP7 revealed the lowest mortality rate of 0.4807 . Conversely, low expression levels of CASP1 were associated with the highest mortality rate of 0.7680 .

As presented in Table II, increased expression of CASP1, CASP3 and CASP7 was linked to OS in patients with GC of pathological grade I. CASP2 and CASP5 were associated with stage II-IV GC, while CASP4 and CASP8 were associated with stage I and III GC, and CASP6 was linked to stage III 
A

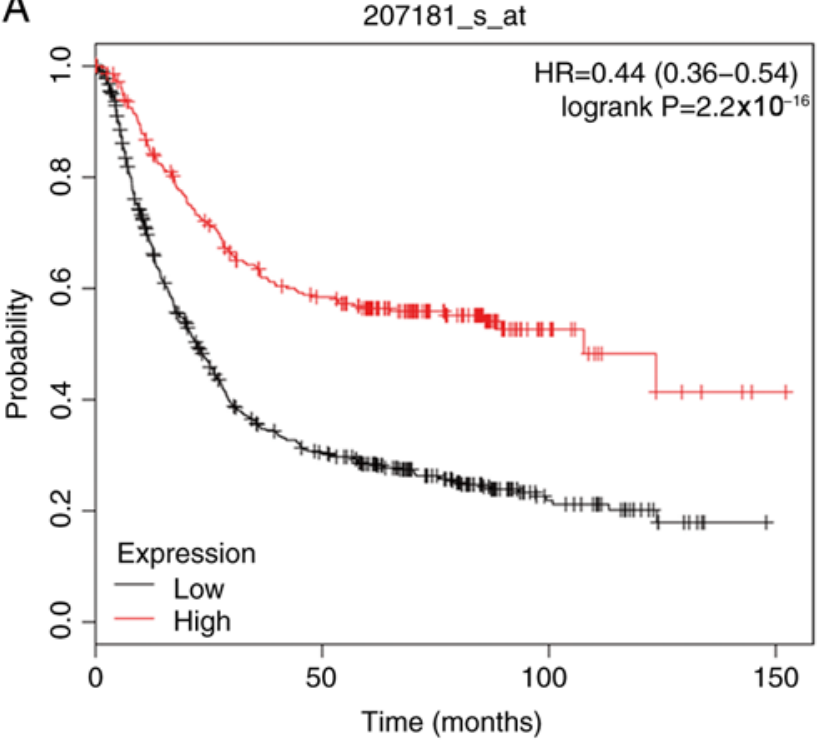

Number at risk

$\begin{array}{llll}\text { Low } 591 & 150 & 30 & 0 \\ \text { High } 285 & 148 & 18 & 1\end{array}$

C

207181_s_at

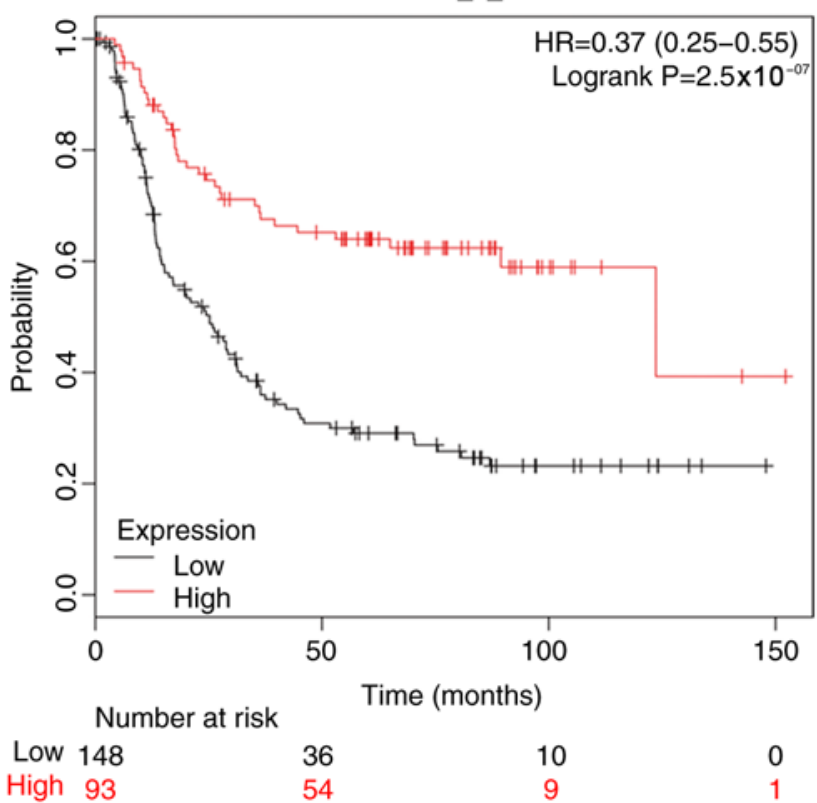

B

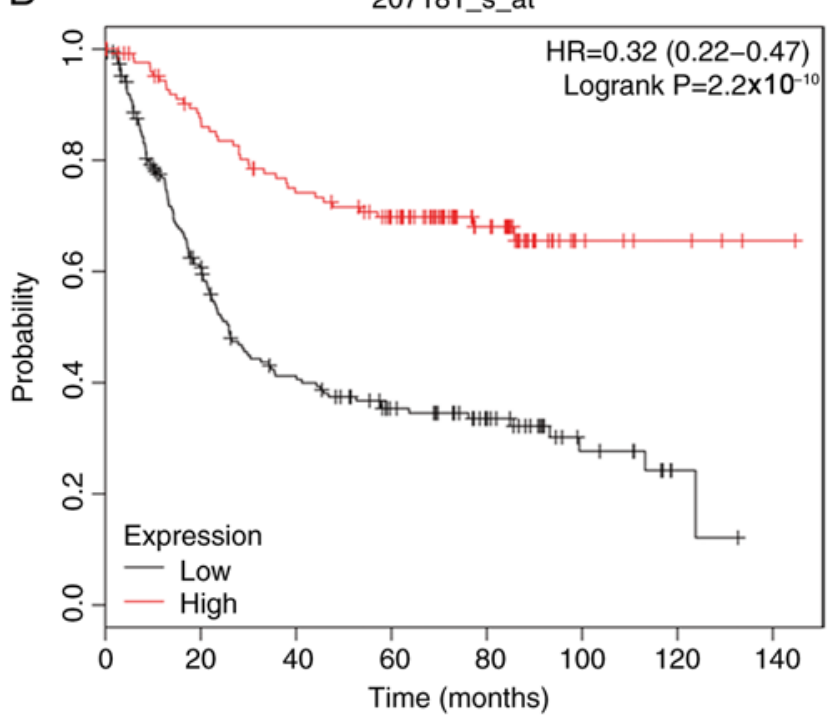

\section{Number at risk}

$\begin{array}{cccccccc}\text { Low 192 } & 103 & 66 & 44 & 29 & 11 & 2 & 0 \\ \text { High 128 } & 105 & 86 & 72 & 37 & 7 & 4 & 1\end{array}$

D

207181_s_at

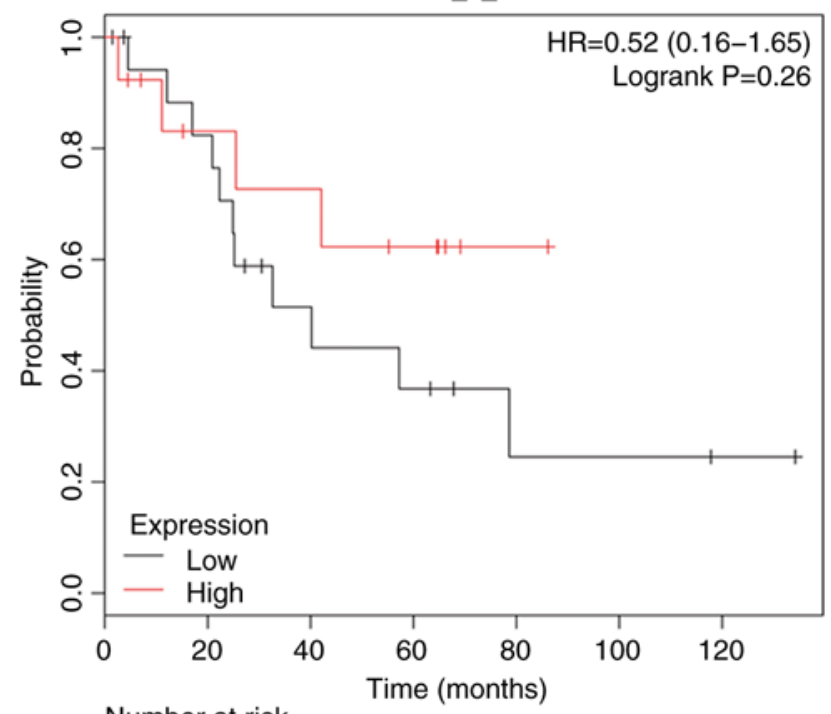

Number at risk

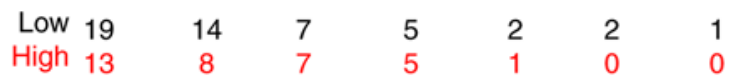

Figure 7. The prognostic significance of CASP7 expression in GC. The prognostic value of CASP7 expression in www.kmplot.com. Affymetrix ID for CASP7: 207181_s_at. OS curves were plotted for (A) all patients $(n=876)$, (B) patients with intestinal cancer $(n=320)$, (C) patients with diffuse cancer ( $n=241)$ and (D) patients with mixed cancer ( $\mathrm{n}=32$ ). GC, gastric cancer; OS, overall survival; CASP7, caspase 7; HR, hazard ratio.

GC. In addition, CASP10 and CASP14 were revealed to be associated with unfavorable OS in stages III and IV of GC; CASP9 was linked to poor OS in stage I and III GC. On the contrary, CASP10 overexpression corresponded to improved OS in patients with stage II GC.

In the present study, the association between CASP expression and HER2 status was investigated in GC patients (Table III). Positive and negative HER2 expression were linked to favorable OS and CASP1, CASP3, CASP5, CASP5, CASP6 and CASP8 mRNA expression. Conversely, CASP2 and CASP4 was associated with negative HER2 status in patients with GC. Analysis of CASP14 with positive or negative HER2 expression was associated with unfavorable OS; CASP10 and CASP12 indicated poorer OS with negative HER2 expression.

As for the treatment strategy, CASP1 was significantly associated with better OS, in all three groups (surgery alone, 5-FU-based adjuvant and other adjuvant; $\mathrm{P}<0.001$; Table IV). The 5-FU-based adjuvant group exhibited an increased HR with CASP2, CASP4, CASP5 and CASP9 mRNA expression. Overexpression of other CASPs was associated with improved OS with each treatment (Table IV).

As presented in Table V, sex, expression status and the expression of CASP1-8, were associated with better OS in 
A

213373_s_at

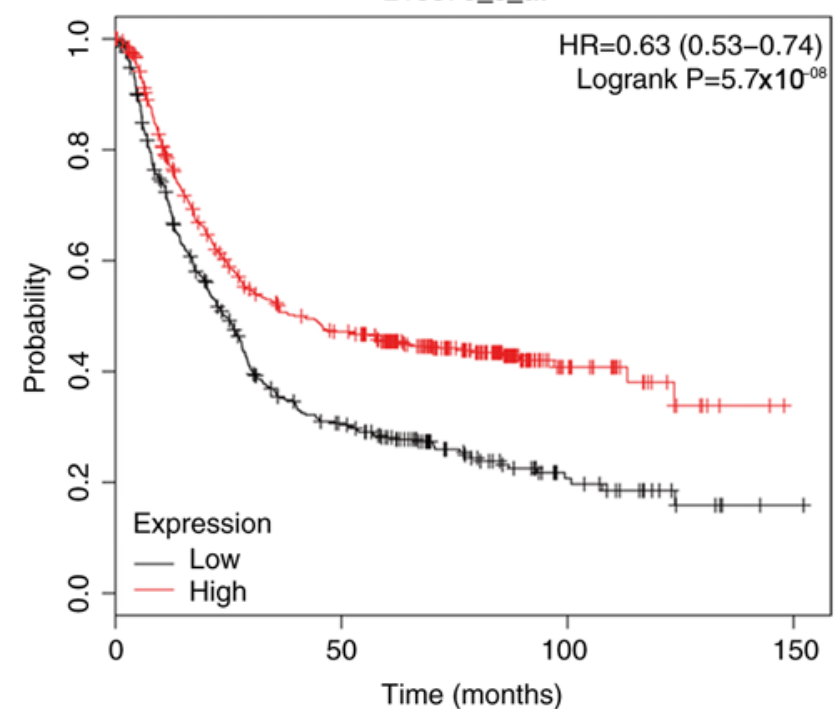

Number at risk

$\begin{array}{lccc}\text { Low 390 } & 99 & 20 & 1 \\ \text { High 486 } & 199 & 28 & 0\end{array}$

C

213373_s_at

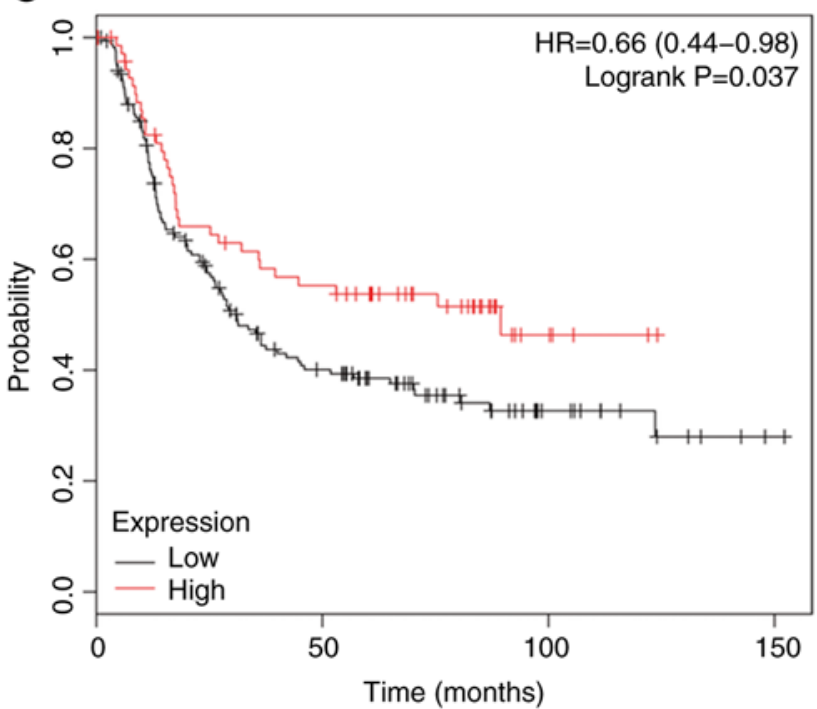

Number at risk

Low 170

High 71

\section{4}

36
13

6
B

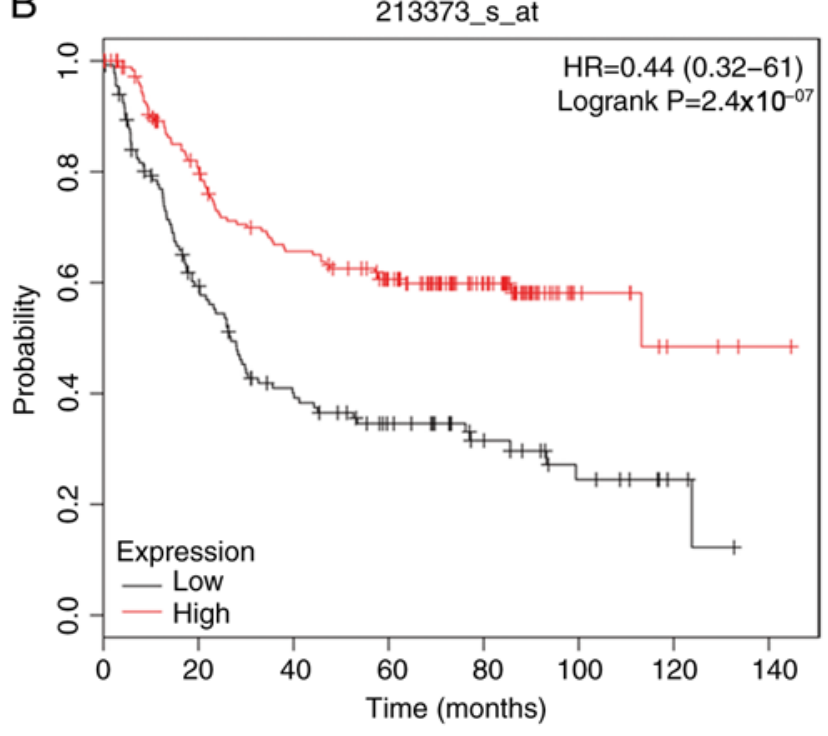

\section{Number at risk}

$\begin{array}{cccccccc}\text { Low } 134 & 73 & 45 & 31 & 18 & 9 & 3 & 0 \\ \text { High } 186 & 135 & 107 & 85 & 48 & 9 & 3 & 1\end{array}$

D

213373_s_at

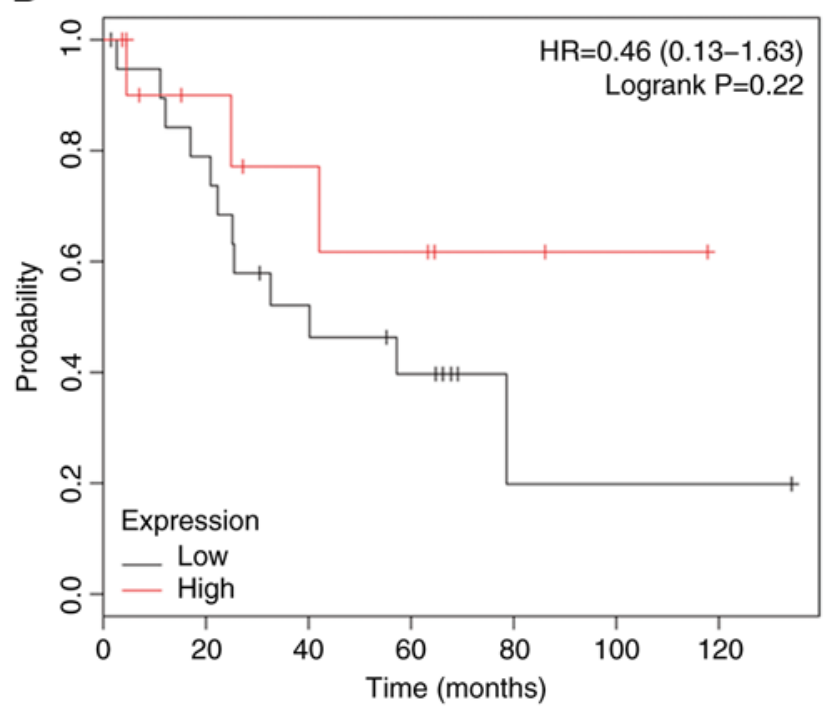

Number at risk

$\begin{array}{ccccccc}\text { Low } 20 & 15 & 9 & 6 & 1 & 1 & 1 \\ \text { High } 12 & 7 & 5 & 4 & 2 & 1 & 0\end{array}$

Figure 8. The prognostic significance of CASP8 expression in GC. The prognostic value of CASP8 expression in www.kmplot.com. Affymetrix ID for CASP8: 213373_s_at. OS curves were plotted for (A) all patients $(n=876)$, (B) patients with intestinal cancer $(n=320)$, (C) patients with diffuse cancer $(n=241)$ and (D) patients with mixed cancer $(\mathrm{n}=32)$. GC, gastric cancer; OS, overall survival; CASP8, caspase 8; HR, hazard ratio.

male and female patients with GC. Nevertheless, CASP10 and CASP14 were associated with poor OS regardless of sex.

Based on the differentiation degree of GC (Table VI), increased CASP2, CASP4, CASP5 and CASP8 expression under moderate differentiation was associated with poor OS. GC of a poor differentiation degree with upregulated CASP1 and CASP8 expression was positively associated with OS.

\section{Discussion}

In the present study, the KM plotter was employed to determine the association between CASP gene expression and OS in GC. The results revealed that CASP1-8 were associated with improved OS for patients with GC, whereas high expression of CASPs 9, 10, 12 and 14 were linked to poor OS. In the CASP3 subfamily, all components except CASP10 were positively associated with improved OS in GC.

Caspase 8 , as an initiator, is activated by associating with death-inducing signaling complex of the extracellular pathway and cleaves procaspases 3, 4, 7, 9 and 10 and/or activates Bid. This leads to mitochondrial permeabilization executed by BCL2-associated X protein and BCL2 antagonist/killer protein (5). As for the association between CASPs and cancer, Du et al (13) explored the effects of a six-nucleotide deletion 
A

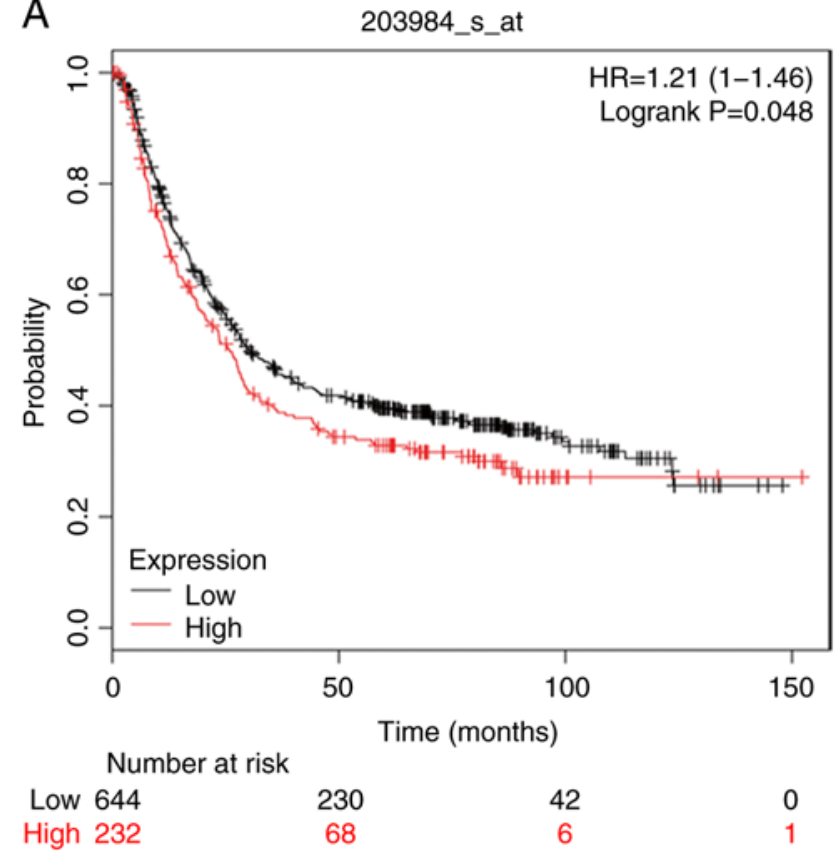

C

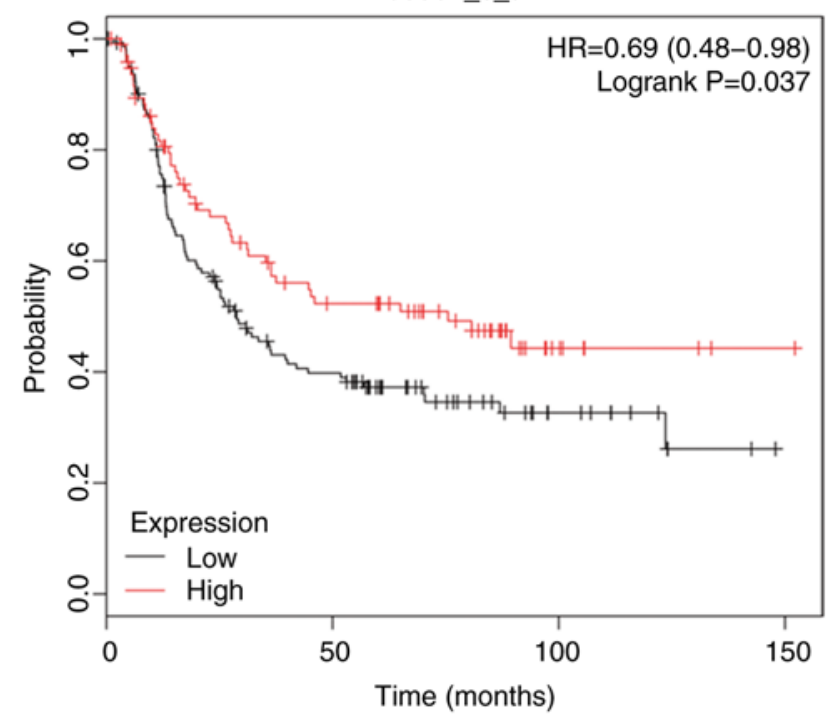

Number at risk

$\begin{array}{cccc}\text { Low } 144 & 49 & 11 & 0 \\ \text { High } 97 & 41 & 8 & 1\end{array}$

B

203984_s_at

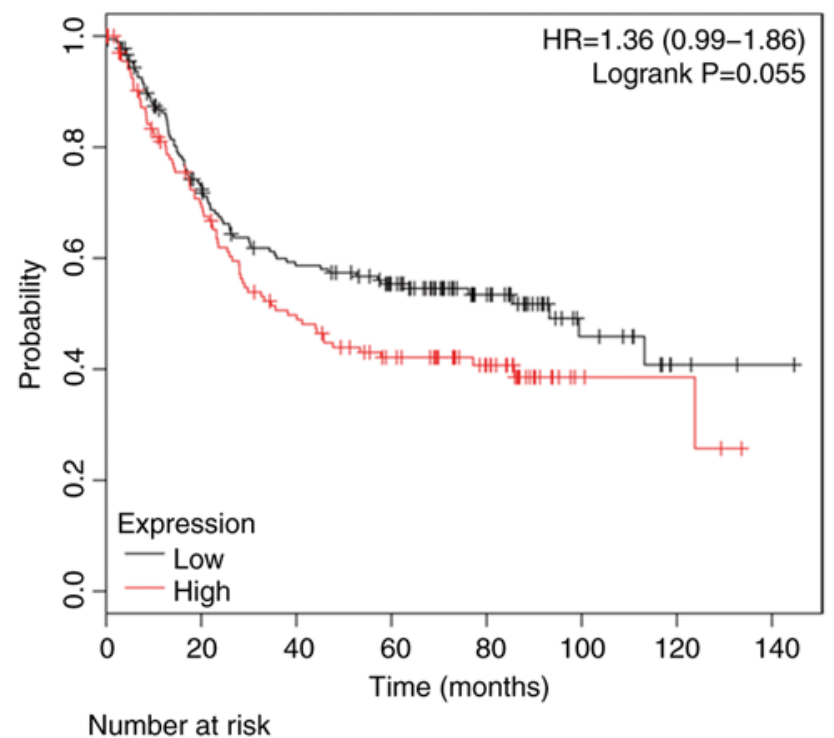

$\begin{array}{cccccccc}\text { Low } 181 & 120 & 92 & 73 & 40 & 14 & 3 & 1 \\ \text { High } 139 & 88 & 60 & 43 & 26 & 4 & 3 & 0\end{array}$

D

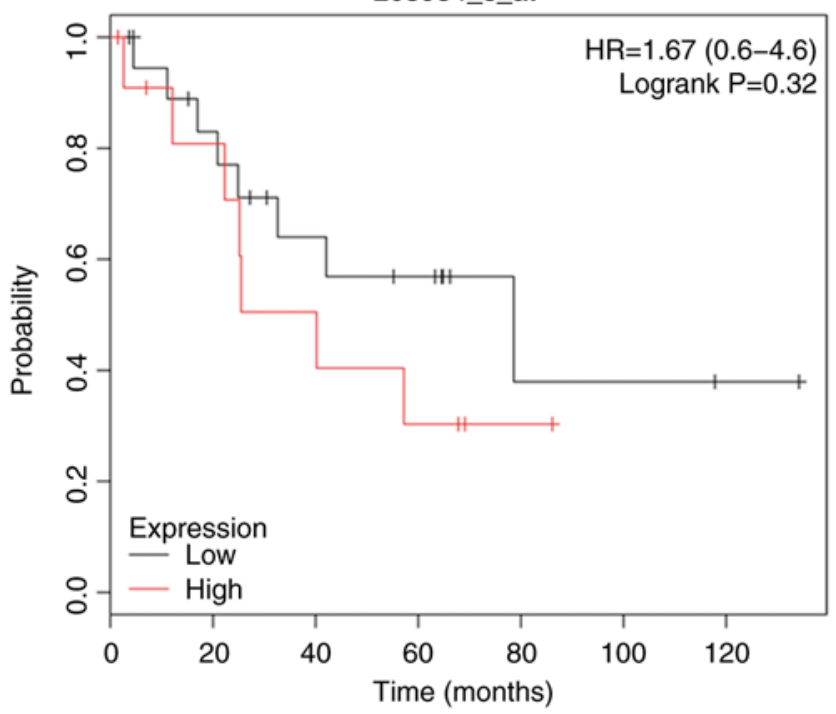

Number at risk

$\begin{array}{ccccccc}\text { Low } 20 & 14 & 9 & 7 & 2 & 2 & 1 \\ \text { High } 12 & 8 & 5 & 3 & 1 & 0 & 0\end{array}$

Figure 9. The prognostic significance of CASP9 expression in GC. The prognostic value of CASP9 expression in www.kmplot.com. Affymetrix ID for CASP9: 203984_s_at. OS curves were plotted for (A) all patients $(n=876)$, (B) patients with intestinal cancer $(n=320)$, (C) patients with diffuse cancer $(n=241)$ and (D) patients with mixed cancer ( $\mathrm{n}=32$ ). GC, gastric cancer; OS, overall survival; CASP9, caspase 9; HR, hazard ratio.

polymorphism of the CASP8 gene in the digestive tract on the risk of cancer development; all genetic models exhibited protection against the development of GC. The antitumor effects of CASPs were also investigated by Kanehara et al (14), in which the degree of CASP8 activation could indicate the anticancer potential of this CASP. Apart from GC, CASP8 has been reported to sense proliferation-associated DNA damage and may serve as an indicator of liver cancer (15). Of note, apoptosis induced by aspirin and vitamin E succinate in GC has been reported to involve CASP8 $(16,17)$.

CASPs 3, 6 and 7 act as executioners of apoptosis, causing programmed cell death by hydrolysis of the caspase target protein.
CASP3 acts on poly(ADP-ribose)polymerase (PARP), DNA-PK, Rho GDP-dissociation inhibitor (RhoGDI), sterol regulatory element-binding protein (SREBP) and CKq and can be activated by CASPs 8,9 and 10. PARP is a multifunctional protein involved in post-translational modifications in the majority of eukaryotic cells. PARP has been considered to be a receptor for DNA damage as it is activated by recognizing DNA fragments that are structurally damaged. It performs poly ADP-ribosylation on a variety of nuclear proteins; histones detach from DNA via the ADP-ribosylation of histones for the binding of repair proteins, promoting the repair of damaged DNA. In vivo, PARP is the main cleavage target of CASP3. 
A

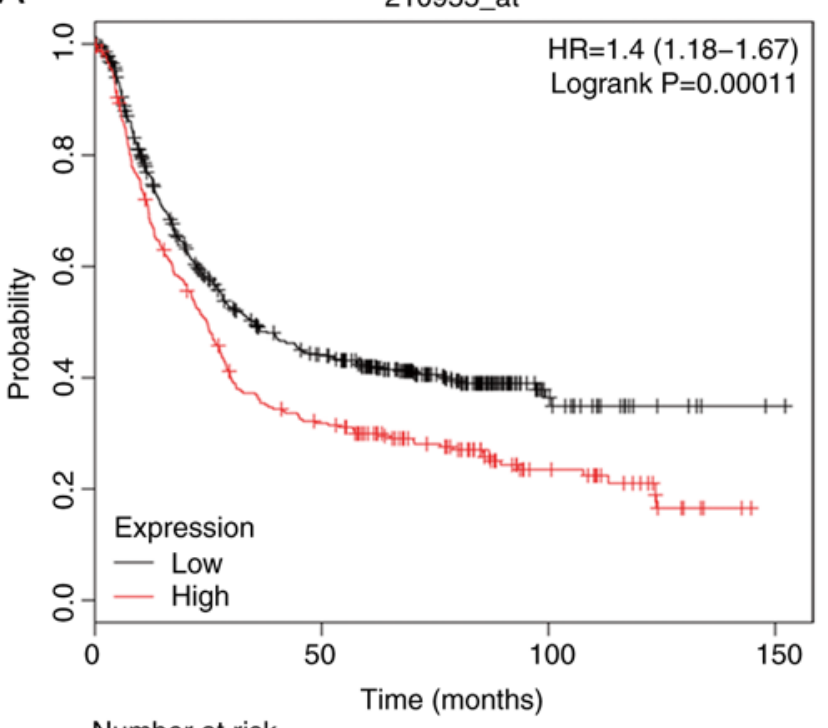

Number at risk

Low 582

High 294

C

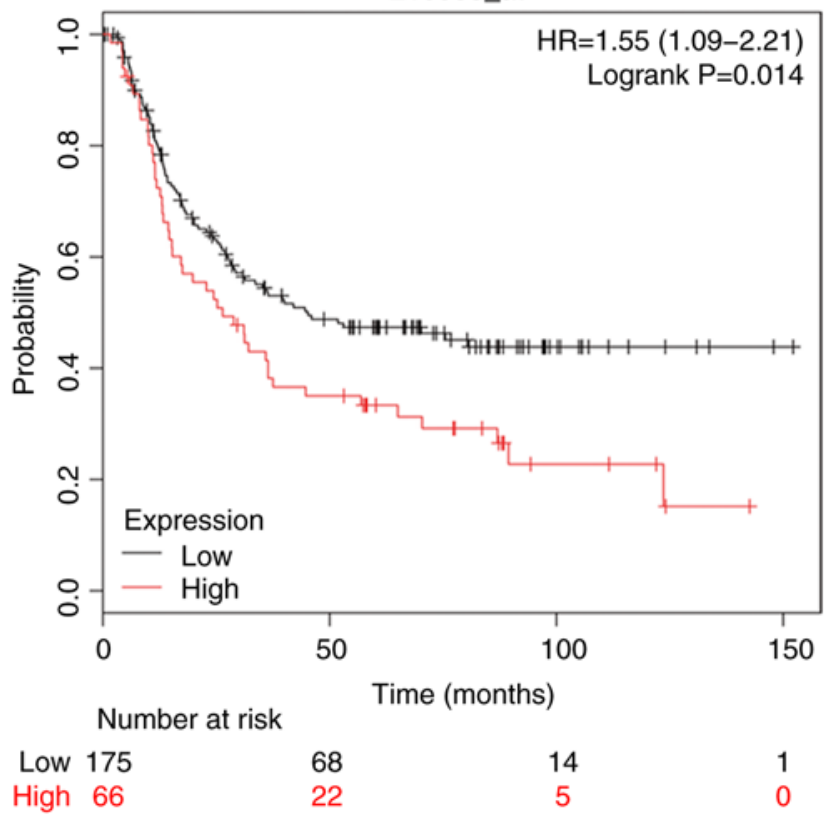

B

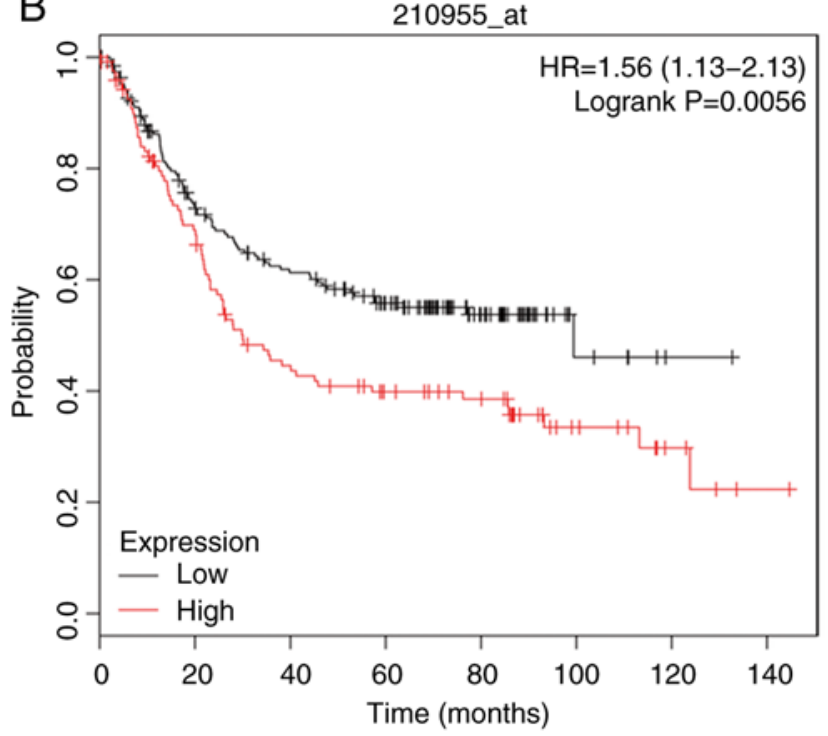

Number at risk

\begin{tabular}{|c|c|c|c|c|}
\hline Low 195 & 130 & 104 & 80 & 36 \\
\hline High 125 & 78 & 48 & 36 & 30 \\
\hline
\end{tabular}

D

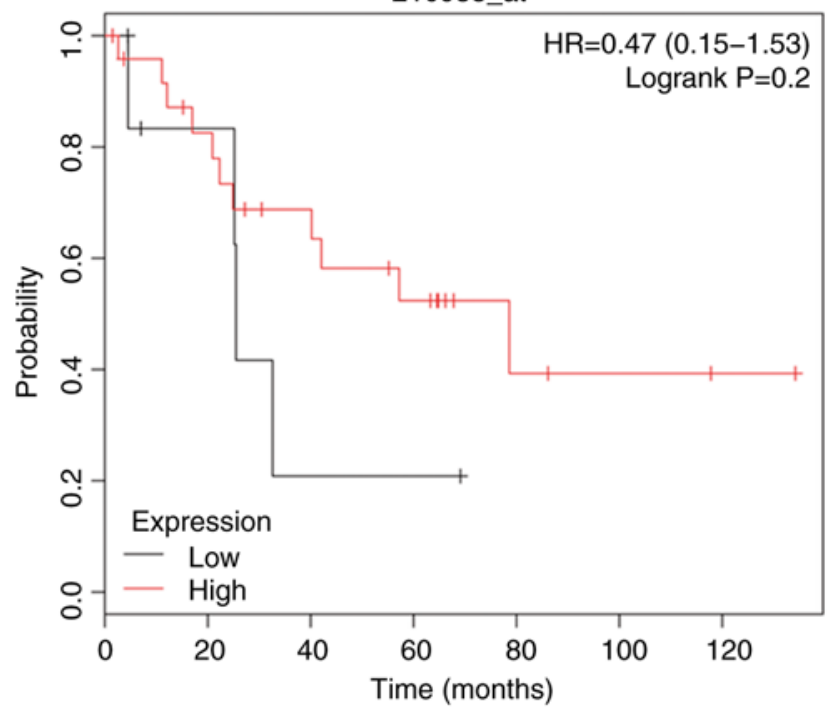

Number at risk

\begin{tabular}{|c|c|c|c|c|}
\hline Low 7 & 4 & 1 & 1 & . \\
\hline High 25 & 18 & 13 & 9 & 3 \\
\hline
\end{tabular}

Figure 10. The prognostic significance of CASP10 expression in GC. The prognostic value of CASP10 expression in www.kmplot.com. Affymetrix ID for CASP10: 210955_at. OS curves were plotted for (A) all patients $(n=876),(B)$ patients with intestinal cancer $(n=320)$, (C) patients with diffuse cancer ( $\mathrm{n}=241)$ and (D) patients with mixed cancer ( $\mathrm{n}=32$ ). GC, gastric cancer; OS, overall survival; CASP10, caspase 10; HR, hazard ratio.

Human PARP is cleaved between Asp124 and Gly215, separating its catalytic domain at the carboxyl end and the domain at the amino terminus; thus, PARP loses its enzymatic activity. The cleavage of PARP has been considered to be an important indicator of apoptosis and an indicator of CASP3 activation. Additionally, PARP can be activated by CASP7. A variety of therapeutic agents, including resveratrol, berberine, homoharringtonine and silibinin can inhibit interactions between CASP3 and PARP and are applied for the treatment of breast cancer, human epidermoid carcinoma, leukemia and human bladder transitional cell carcinoma (18-21). DNA-PK is a key protein kinase involved the process of genomic DNA damage repair via non-homologous end joining and maintains telomere stability. DNA damage reparation can affect the sensitivity of genotoxic drugs to cancer cells. Thus, in clinical settings, inhibiting the activity of DNA-PK may be an effective anticancer strategy. DNA-PK and PARP inhibitors have been applied as chemo-/radio-sensitizers in Ewing sarcoma (22). Similarly, Alikarami et al (23) indicated that inhibition of DNA-PK increased the chemosensitivity of B-cell precursor acute lymphoblastic leukemia to doxorubicin. The negative association between the content of DNA-PK and CASP3 supports the results of the present study in which CASP3 expression may improve the OS of patients with GC. RhoGDI2, is a member 
A

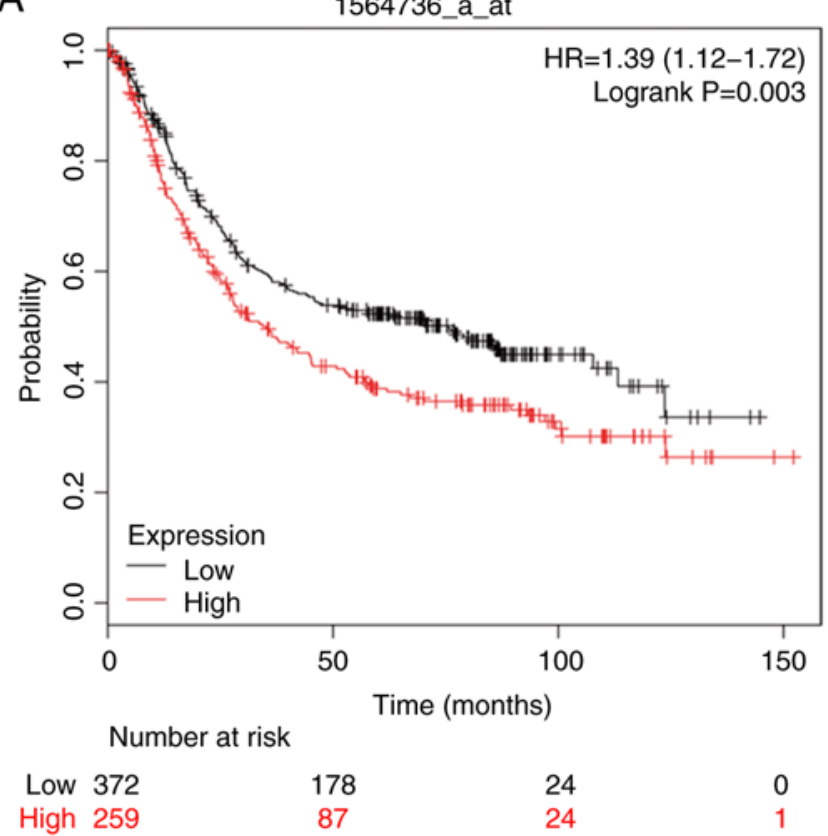

C

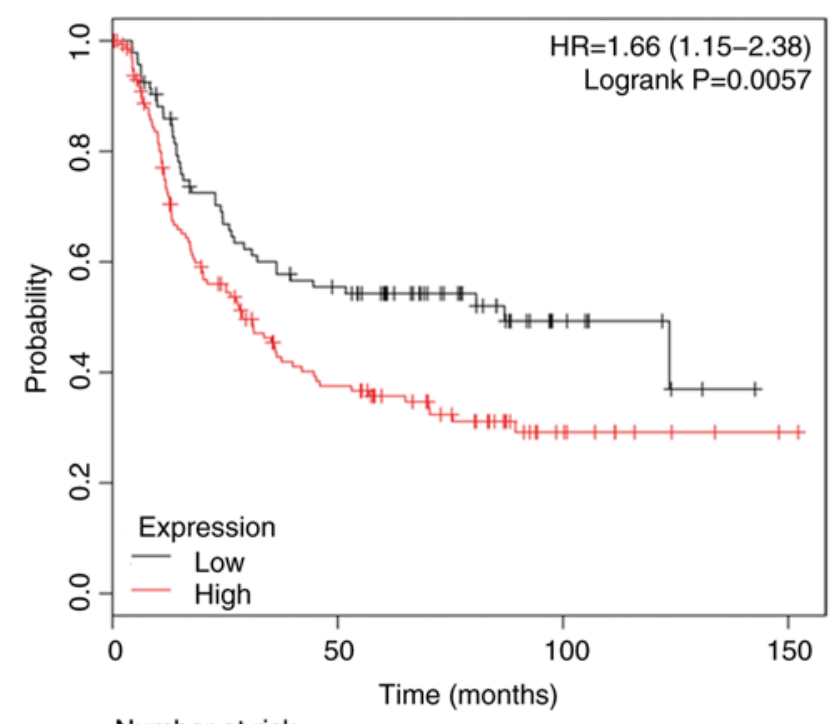

Number at risk
B

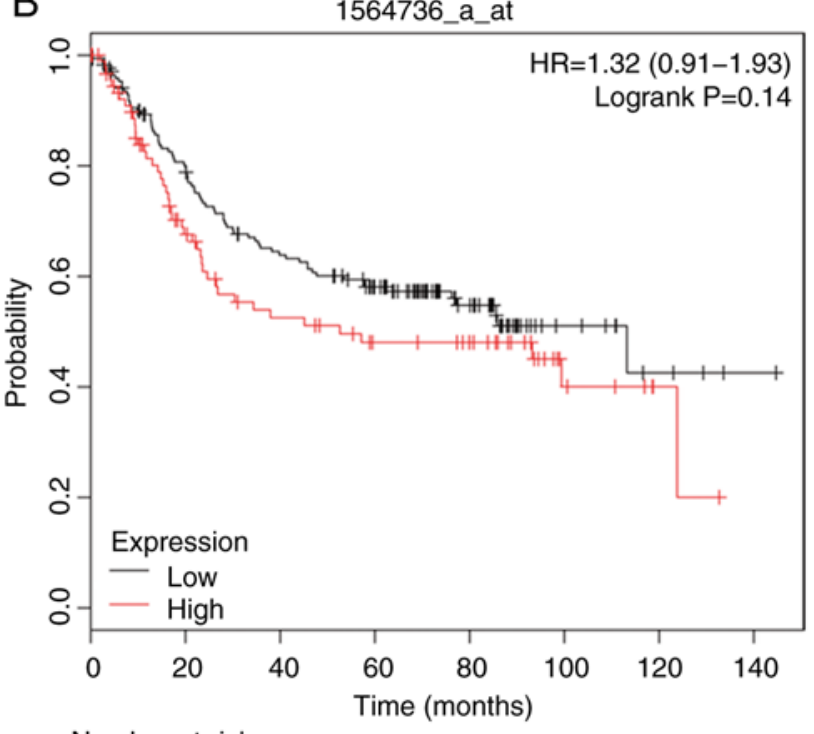

Number at risk

\begin{tabular}{|c|c|c|c|c|c|}
\hline w 175 & 130 & 101 & 79 & 41 & 10 \\
\hline High 94 & 52 & 37 & 29 & 24 & 8 \\
\hline
\end{tabular}

D 1564736_a_at

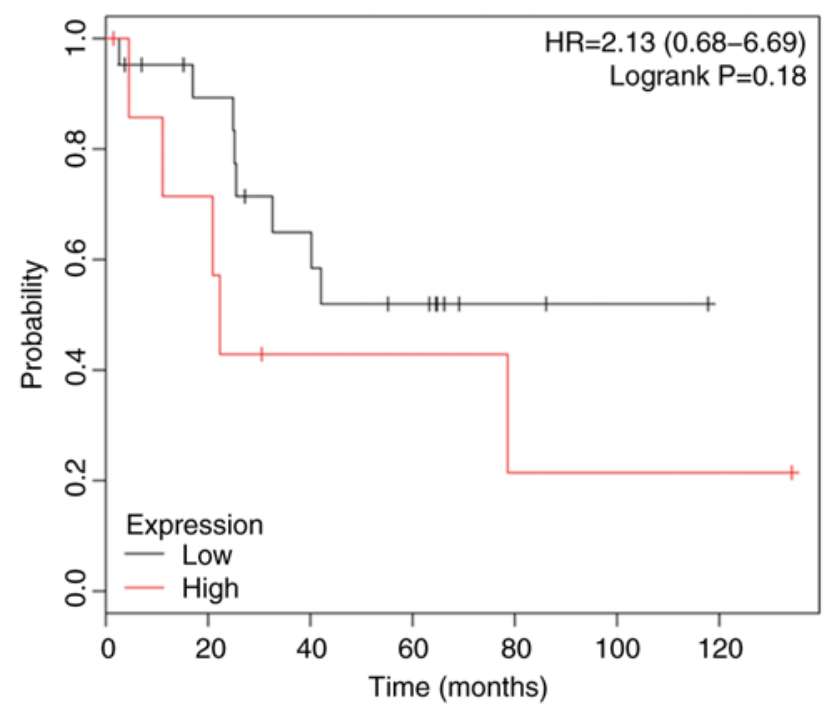

Number at risk

$\begin{array}{ccccccc}\text { Low } 21 & 15 & 10 & 7 & 2 & 1 & 0 \\ \text { High } 8 & 5 & 2 & 2 & 1 & 1 & 1\end{array}$

Figure 11. The prognostic significance of CASP12 expression in GC. The prognostic value of CASP12 expression in www.kmplot.com. Affymetrix ID for CASP12: 1564736_a_at. OS curves were plotted for (A) all patients $(n=631)$, (B) patients with intestinal cancer $(n=269)$, (C) patients with diffuse cancer $(n=240)$ and $(D)$ patients with mixed cancer $(n=29)$. GC, gastric cancer; OS, overall survival; CASP12, caspase 12; HR, hazard ratio.

of RhoGDI family of proteins. In GC, RhoGDI2 is correlated with cancer growth, metastasis and chemoresistance (24). Regarding the underlying mechanism, RhoGDI2 upregulates vascular endothelial growth factor (VEGF)-C expression, which promotes cancer cell invasion and induces cisplatin resistance. Of note, RhoGDI2 positively regulates Racl activity, which can suppress VEGF-C expression (24). Furthermore, RhoGDI2 is associated with 5-FU resistance (25). As a potential therapeutic target, during drug-induced apoptosis, RhoGDI2 is cleaved by CASP3 (26). RhoGDI-signaling and mevalonate, as well as mitochondrial metabolism, could be targeted by bergamot natural products to eradicate cancer stem cells (27).
CASP6 can be activated by CASPs 7 and 3 and act on lamin A, the main component of the basal lamina. It is a dynamic network located beneath the nuclear membrane and serves an important mechanical role, and can directly or indirectly interact with chromatin. Lamin A serves a major role in maintaining chromatin structure, transcription, DNA replication and apoptosis. Wu et al (28) indicated that downregulation of lamin A was an independent risk factor for the poor prognosis of GC; however, the effects of CASP6 and lamin A on GC require further investigation. As for CASP7, SREBP-1 and -2 may bind to the proximal promoter region of the CASP7 gene, inducing its expression (29). 
A

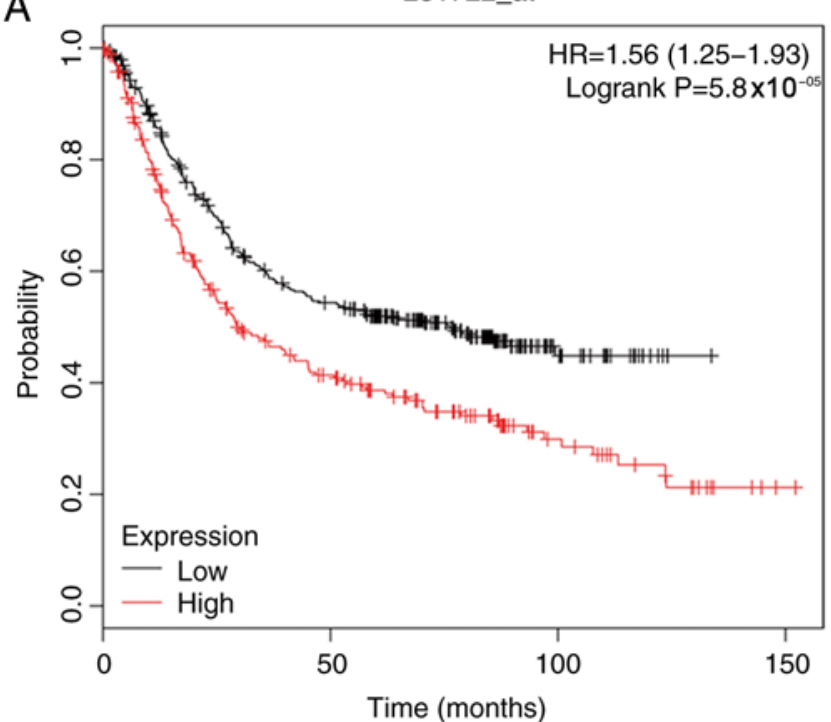

Number at risk

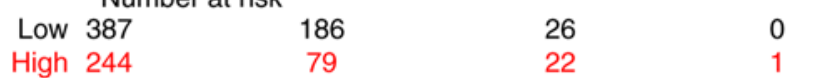

C

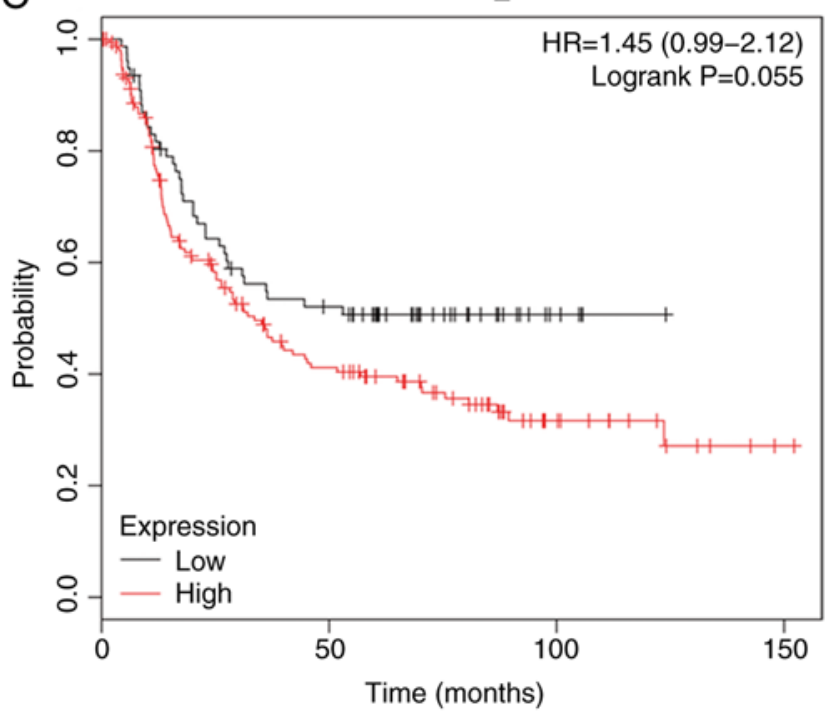

$$
\text { Number at risk }
$$$$
\text { Low } 77
$$

High 163 231722_at

$\begin{array}{ccc}37 & 5 & 0 \\ 53 & 14 & 1\end{array}$

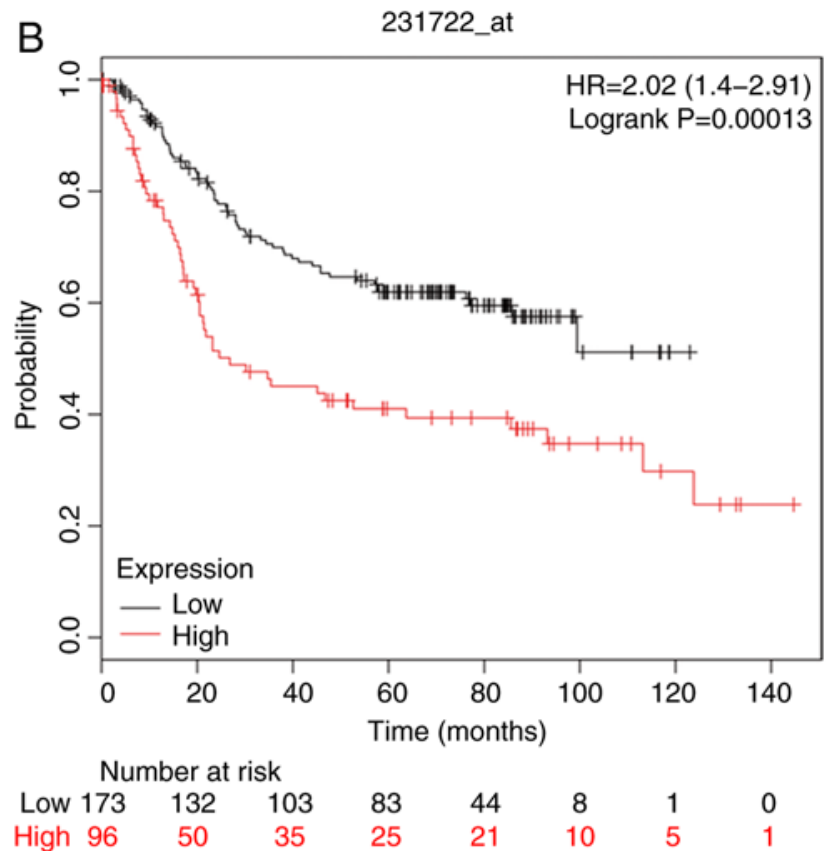

D 231722_at

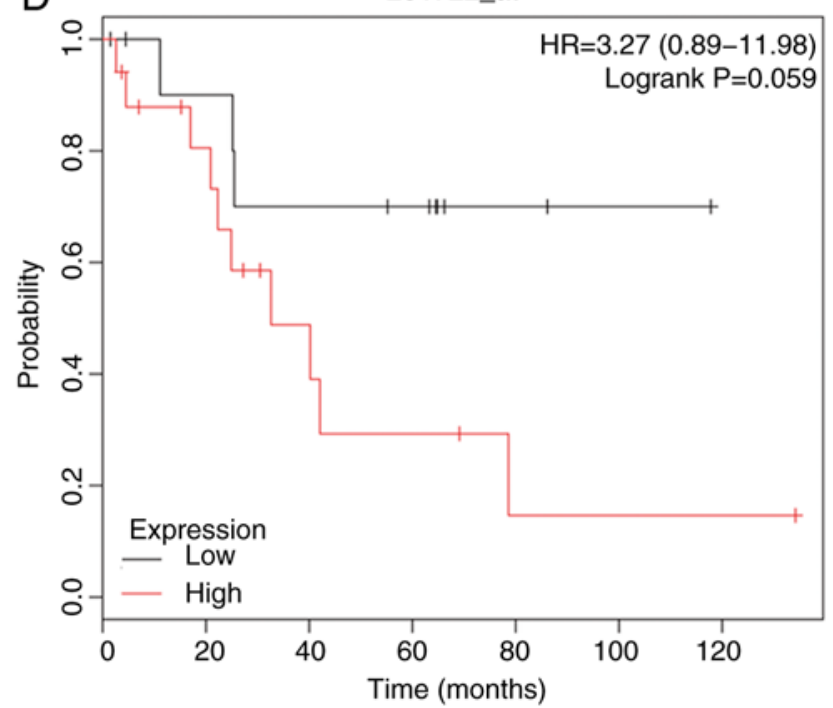

\begin{tabular}{ccccccc}
\multicolumn{2}{c}{ Number at risk } & & & & & \\
Low 12 & 9 & 7 & 6 & 2 & 1 & 0 \\
High 17 & 11 & 5 & 3 & 1 & 1 & 1
\end{tabular}

Figure 12. The prognostic significance of CASP14 expression in GC. The prognostic value of CASP14 expression in www.kmplot.com. Affymetrix ID for CASP14: 231722_at. OS curves were plotted for (A) all patients $(n=631)$, (B) patients with intestinal cancer $(n=269)$, (C) patients with diffuse cancer ( $\mathrm{n}=240)$ and (D) patients with mixed cancer $(n=29)$. GC, gastric cancer; OS, overall survival; CASP14, caspase 14; HR, hazard ratio.

CASP10 may affect the apoptosis of GC cells by acting as an initiator, which has been associated with poor OS. It can be activated by procaspase 8 and TRADD in the extrinsic pathway and acts on CASP3. Additionally, CASP10 has been associated with cancer. For instance, in myeloma, the survival of cancer cells is dependent in CASP10 as myeloma cells require a basal level of autophagy to survive; however, CASP10 regulates this response to prevent cell death, promoting disease progression (30).

The CASP1 subfamily, including CASPs 1, 4, 5, 11, 12 and 14, exhibited a positive association with improved OS. CASP1 can activate CASPs 3 and 4, as well as interleukin (IL)-1 and IL-18; conversely, CASP4 can also activate CASP1.
CASP3 has been reported to act as an executioner. Therefore, CASP1 can indirectly promote apoptosis, indicating a positive association with improved OS in GC. Regarding ILs, active CASP1 processes pro-IL-1 $\beta$ and pro-IL-18 to initiate immune responses; IL-18, counteracts the effects of IL-1 $\beta$, which has proinflammatory activities similar to another CASP1 substrate, in order to control disease by preventing hyperactivation of the immune response in the gastric tissues (31).

As for CASP4, this protein can be activated by declines in adenosine deaminase activity and could induce gastric epithelial cell apoptosis, promoting the formation of gastric ulcers; however, a small population of cells may undergo malignant transformation (32). The diagnostic value of adenosine 
Table I. Association between CASP gene expression levels and mortality at 50 months in patients with gastric cancer.

\begin{tabular}{|c|c|c|c|c|c|}
\hline CASP & Expression & $\mathrm{N}$ & Surviving patients & Mortality rate & P-value \\
\hline \multirow[t]{2}{*}{ CASP1 } & Low & 375 & 87 & 0.768000 & $<0.001^{\mathrm{a}}$ \\
\hline & High & 501 & 211 & 0.578842 & \\
\hline \multirow[t]{2}{*}{ CASP2 } & Low & 348 & 121 & 0.652299 & $<0.001^{\mathrm{a}}$ \\
\hline & High & 283 & 144 & 0.491166 & \\
\hline \multirow[t]{2}{*}{ CASP3 } & Low & 519 & 129 & 0.751445 & $<0.001^{\mathrm{a}}$ \\
\hline & High & 357 & 169 & 0.526611 & \\
\hline \multirow[t]{2}{*}{ CASP4 } & Low & 655 & 198 & 0.697710 & $<0.001^{\mathrm{a}}$ \\
\hline & High & 221 & 100 & 0.547511 & \\
\hline \multirow[t]{2}{*}{ CASP5 } & Low & 447 & 121 & 0.729306 & $<0.001^{\mathrm{a}}$ \\
\hline & High & 429 & 177 & 0.587413 & \\
\hline \multirow[t]{2}{*}{ CASP6 } & Low & 483 & 139 & 0.712215 & $<0.001^{\mathrm{a}}$ \\
\hline & High & 393 & 159 & 0.595420 & \\
\hline \multirow[t]{2}{*}{ CASP7 } & Low & 591 & 150 & 0.746193 & $<0.001^{\mathrm{a}}$ \\
\hline & High & 285 & 148 & 0.480702 & \\
\hline \multirow[t]{2}{*}{ CASP8 } & Low & 390 & 99 & 0.746154 & $<0.001^{\mathrm{a}}$ \\
\hline & High & 486 & 199 & 0.590535 & \\
\hline \multirow[t]{2}{*}{ CASP9 } & Low & 644 & 230 & 0.642857 & $<0.001^{\mathrm{a}}$ \\
\hline & High & 232 & 68 & 0.706897 & \\
\hline \multirow[t]{2}{*}{ CASP10 } & Low & 582 & 211 & 0.637457 & $<0.001^{\mathrm{a}}$ \\
\hline & High & 294 & 87 & 0.704082 & \\
\hline \multirow[t]{2}{*}{ CASP12 } & Low & 372 & 178 & 0.521505 & $<0.001^{\mathrm{a}}$ \\
\hline & High & 259 & 87 & 0.664093 & \\
\hline \multirow[t]{2}{*}{ CASP14 } & Low & 387 & 186 & 0.519380 & $<0.001^{\mathrm{a}}$ \\
\hline & High & 244 & 79 & 0.676230 & \\
\hline
\end{tabular}

${ }^{a} \mathrm{P}<0.05$. CASP1, caspase 1; CASP2, caspase 2; CASP3, caspase 3; CASP4, caspase 4; CASP5, caspase 5; CASP6, caspase 6; CASP7, caspase 7; CASP8, caspase 8; CASP9, caspase 9; CASP10, caspase 10; CASP12, caspase 12; CASP14, caspase 14.

deaminase is of less importance as its activity in GC did not significantly differ to that in normal mucosa (33). CASP4 could act as a novel diagnostic and prognostic biomarker of non-small cell lung cancer as reported by Terlizzi et al (34); however, further investigation is required.

CASP5 is an inflammatory caspase; together with CASP11, these proteins serve a role in the immune system. The association between inflammation and cancer has been reported, and it is widely accepted that the tumor-promoting inflammatory environment is one of the major hallmarks of cancer (35). In combination with the results of the present study that CASPs 5 and 11 were linked to improved OS, it was proposed that these proteins may serve roles in inflammation. In addition, several studies have reported supporting findings. Viganò et al (36) revealed that CASP5 was a key determinant of one-step inflammasome activation mediated by IL- $1 \alpha$ and IL- $1 \beta$ release in human monocytes, following treatment with lipopolysaccharide. Regarding CASP11, knockout experiments revealed that in CASP $11^{-/-}$mice, the levels of IL-1 $\beta$ and IL-18 in the colon were significantly reduced compared with wild-type mice. This suggested a possible mechanism in which CASP11 may attenuate acute experimental colitis. CASP11 has been reported to serve an important role in suppressing the development of acute colitis, but may also be involved in chronic relapsing-remitting colitis and inflammation-driven colon tumorigenesis (37).

CASP12 has unique characteristics that are not mutual to other family members, as is activated via endoplasmic reticulum (ER) stress-induced cell death, rather than the intrinsic and extrinsic pathways. ER stress is the consequence of abnormal calcium absorption and is released from the ER. The activation of CASP12 via its cleavage may proceed by proteases present on the surface of the ER membrane, such as calpain. Intracellular calcium elevation accounts for the activation and transport of calpain and other ER-associated proteins to the ER surface. As an alternative method of activation, CASP7 on the ER surface is capable of cleaving procaspase12 $(38,39)$. With respect to downstream substrates, procaspase 9 is a substrate that is cleaved at the processing site, transmitting proteolytic signals to CASP3 (38). The direct activation of CASP9 may be associated with poor OS. Additionally, CASP12 as a truncated or full-length proenzyme may arise from the single nucleotide polymorphism of CASP12, impairing the innate immune and inflammatory responses to infection in carcinoma, increasing the risk of sepsis (40).

Van de Craen et al (41) revealed that procaspase 14 can be weakly cleaved by CASP8 into active fragments, which did not result in the subsequent cleavage of the classical CASP family 
Table II. Association between CASP gene expression levels and OS in patients with gastric cancer based on pathological stages.

\begin{tabular}{|c|c|c|c|c|}
\hline CASPs & Pathological grade & $\mathrm{N}$ & $\mathrm{HR}(95 \% \mathrm{CI})$ & P-value \\
\hline \multirow[t]{4}{*}{ CASP1 } & I & 67 & $0.28(0.1-0.75)$ & $0.007^{\mathrm{a}}$ \\
\hline & II & 140 & $0.48(0.24-0.96)$ & $0.034^{\mathrm{a}}$ \\
\hline & III & 305 & $0.43(0.32-0.57)$ & $<0.001^{\mathrm{a}}$ \\
\hline & IV & 148 & $0.6(0.41-0.88)$ & $0.009^{\mathrm{a}}$ \\
\hline \multirow[t]{4}{*}{ CASP2 } & I & 62 & $0.62(0.21-1.86)$ & 0.390 \\
\hline & II & 135 & $0.44(0.23-0.84)$ & $0.010^{\mathrm{a}}$ \\
\hline & III & 197 & $0.63(0.43-0.93)$ & $0.018^{\mathrm{a}}$ \\
\hline & IV & 140 & $0.51(0.32-0.81)$ & $0.004^{\mathrm{a}}$ \\
\hline \multirow[t]{4}{*}{ CASP3 } & $\mathrm{I}$ & 67 & $0.32(0.11-0.88)$ & $0.020^{\mathrm{a}}$ \\
\hline & II & 140 & $0.32(0.14-0.71)$ & $0.003^{\mathrm{a}}$ \\
\hline & III & 305 & $0.42(0.29-0.62)$ & $<0.001^{\mathrm{a}}$ \\
\hline & IV & 148 & $0.55(0.34-0.87)$ & $0.010^{\mathrm{a}}$ \\
\hline \multirow[t]{4}{*}{ CASP4 } & I & 67 & $0.34(0.12-0.95)$ & $0.032^{\mathrm{a}}$ \\
\hline & II & 140 & $0.58(0.32-1.06)$ & 0.071 \\
\hline & III & 305 & $0.49(0.35-0.68)$ & $<0.001^{\mathrm{a}}$ \\
\hline & IV & 148 & $0.83(0.57-1.23)$ & 0.360 \\
\hline \multirow[t]{4}{*}{ CASP5 } & $\mathrm{I}$ & 67 & $2.33(0.84-6.45)$ & 0.096 \\
\hline & II & 140 & $0.44(0.24-0.81)$ & $0.007^{\mathrm{a}}$ \\
\hline & III & 305 & $0.63(0.45-0.88)$ & $0.007^{\mathrm{a}}$ \\
\hline & IV & 148 & $0.51(0.34-0.77)$ & $0.001^{\mathrm{a}}$ \\
\hline \multirow[t]{4}{*}{ CASP6 } & $\mathrm{I}$ & 67 & $0.55(0.19-1.6)$ & 0.270 \\
\hline & II & 140 & $0.68(0.36-1.31)$ & 0.250 \\
\hline & III & 305 & $0.59(0.42-0.83)$ & $0.002^{\mathrm{a}}$ \\
\hline & IV & 148 & $0.79(0.5-1.23)$ & 0.290 \\
\hline \multirow[t]{4}{*}{ CASP7 } & I & 67 & $0.27(0.09-0.84)$ & $0.016^{\mathrm{a}}$ \\
\hline & II & 140 & $0.42(0.23-0.78)$ & $0.005^{\mathrm{a}}$ \\
\hline & III & 305 & $0.36(0.24-0.54)$ & $<0.001^{\mathrm{a}}$ \\
\hline & IV & 148 & $0.47(0.31-0.72)$ & $<0.001^{\mathrm{a}}$ \\
\hline \multirow[t]{4}{*}{ CASP8 } & $\mathrm{I}$ & 67 & $0.27(0.08-0.94)$ & $0.027^{\mathrm{a}}$ \\
\hline & II & 140 & $1.57(0.85-2.89)$ & 0.150 \\
\hline & III & 305 & $0.47(0.35-0.63)$ & $<0.001^{\mathrm{a}}$ \\
\hline & IV & 148 & $0.67(0.43-1.04)$ & 0.072 \\
\hline \multirow[t]{4}{*}{ CASP9 } & $\mathrm{I}$ & 67 & $3.73(1.31-10.62)$ & $0.009^{\mathrm{a}}$ \\
\hline & II & 140 & $1.54(0.85-2.79)$ & 0.160 \\
\hline & III & 305 & $1.48(1.09-2.01)$ & $0.011^{\mathrm{a}}$ \\
\hline & IV & 148 & $0.78(0.49-1.23)$ & 0.280 \\
\hline \multirow[t]{4}{*}{ CASP10 } & $\mathrm{I}$ & 67 & $2.35(0.8-6.85)$ & 0.110 \\
\hline & II & 140 & $0.54(0.29-1)$ & $0.046^{\mathrm{a}}$ \\
\hline & III & 305 & $1.59(1.19-2.12)$ & $0.002^{\mathrm{a}}$ \\
\hline & IV & 148 & $1.51(1.01-2.25)$ & $0.042^{\mathrm{a}}$ \\
\hline \multirow[t]{4}{*}{ CASP12 } & I & 62 & $0.51(0.17-1.59)$ & 0.240 \\
\hline & II & 135 & $0.48(0.25-0.91)$ & $0.022^{\mathrm{a}}$ \\
\hline & III & 197 & $1.38(0.94-2.02)$ & 0.094 \\
\hline & IV & 140 & $0.81(0.54-1.21)$ & 0.300 \\
\hline \multirow[t]{4}{*}{ CASP14 } & $\mathrm{I}$ & 62 & $2.36(0.78-7.15)$ & 0.120 \\
\hline & II & 135 & $0.56(0.27-1.16)$ & 0.110 \\
\hline & III & 197 & $2.21(1.45-3.37)$ & $<0.001^{\mathrm{a}}$ \\
\hline & IV & 140 & $1.85(1.22-2.8)$ & $0.003^{\mathrm{a}}$ \\
\hline
\end{tabular}

aP $<0.05$. CASP1, caspase 1; CASP2, caspase 2; CASP3, caspase 3; CASP4, caspase 4; CASP5, caspase 5; CASP6, caspase 6; CASP7, caspase 7; CASP8, caspase 8; CASP9, caspase 9; CASP10, caspase 10; CASP12, caspase 12; CASP14, caspase 14; OS, overall survival; CI, confidence interval; HR, hazard ratio. 
Table III. Association between CASP gene expression and OS in patients with gastric cancer based on HER2 expression status.

\begin{tabular}{|c|c|c|c|c|c|c|}
\hline CASP & HER2 status & $\mathrm{N}$ & Low & High & HR $(95 \%$ CI $)$ & P-value \\
\hline \multirow[t]{2}{*}{ CASP1 } & Negative & 532 & 139 & 188 & $0.47(0.38-0.6)$ & $1.0 \times 10^{-10 \mathrm{a}}$ \\
\hline & Positive & 344 & 147 & 197 & $0.62(0.48-0.81)$ & $2.8 \times 10^{-4 a}$ \\
\hline \multirow[t]{2}{*}{ CASP2 } & Negative & 429 & 245 & 184 & $0.58(0.44-0.76)$ & $8.0 \times 10^{-5 a}$ \\
\hline & Positive & 202 & 150 & 52 & $0.67(0.43-1.04)$ & $7.2 \times 10^{-2}$ \\
\hline \multirow[t]{2}{*}{ CASP3 } & Negative & 532 & 283 & 249 & $0.43(0.34-0.55)$ & $1.8 \times 10^{-12 a}$ \\
\hline & Positive & 344 & 246 & 98 & $0.67(0.49-0.91)$ & $9.0 \times 10^{-3 a}$ \\
\hline \multirow[t]{2}{*}{ CASP4 } & Negative & 532 & 398 & 134 & $0.56(0.42-0.74)$ & $5.3 \times 10^{-5 a}$ \\
\hline & Positive & 344 & 150 & 194 & $0.87(0.67-1.13)$ & $3.0 \times 10^{-1}$ \\
\hline \multirow[t]{2}{*}{ CASP5 } & Negative & 532 & 236 & 296 & $0.63(0.51-0.79)$ & $5.9 \times 10^{-5 a}$ \\
\hline & Positive & 344 & 238 & 106 & $0.6(0.44-0.8)$ & $5.7 \times 10^{-4 a}$ \\
\hline \multirow[t]{2}{*}{ CASP6 } & Negative & 532 & 192 & 340 & $0.68(0.55-0.86)$ & $1.1 \times 10^{-3 a}$ \\
\hline & Positive & 344 & 179 & 165 & $0.61(0.47-0.79)$ & $2.2 \times 10^{-4 a}$ \\
\hline \multirow[t]{2}{*}{ CASP7 } & Negative & 532 & 351 & 181 & $0.39(0.3-0.51)$ & $8.2 \times 10^{-13 a}$ \\
\hline & Positive & 344 & 256 & 88 & $0.55(0.4-0.77)$ & $3.2 \times 10^{-4 a}$ \\
\hline \multirow[t]{2}{*}{ CASP8 } & Negative & 532 & 239 & 293 & $0.54(0.43-0.67)$ & $3.5 \times 10^{-8 a}$ \\
\hline & Positive & 344 & 256 & 88 & $0.69(0.51-0.95)$ & $2.3 \times 10^{-2 a}$ \\
\hline \multirow[t]{2}{*}{ CASP9 } & Negative & 532 & 325 & 207 & $1.22(0.97-1.52)$ & $9.2 \times 10^{-2}$ \\
\hline & Positive & 344 & 92 & 252 & $0.72(0.55-0.96)$ & $2.5 \times 10^{-2 \mathrm{a}}$ \\
\hline \multirow[t]{2}{*}{ CASP10 } & Negative & 532 & 375 & 157 & $1.53(1.22-1.93)$ & $2.7 \times 10^{-4 a}$ \\
\hline & Positive & 344 & 183 & 161 & $1.21(0.93-1.57)$ & $1.5 \times 10^{-1}$ \\
\hline \multirow[t]{2}{*}{ CASP12 } & Negative & 429 & 192 & 237 & $1.56(1.18-2.04)$ & $1.3 \times 10^{-3 \mathrm{a}}$ \\
\hline & Positive & 202 & 136 & 66 & $1.42(0.96-2.1)$ & $7.7 \times 10^{-2}$ \\
\hline \multirow[t]{2}{*}{ CASP14 } & Negative & 429 & 147 & 282 & $1.59(1.18-2.14)$ & $2.3 \times 10^{-3 a}$ \\
\hline & Positive & 202 & 96 & 106 & $2.09(1.43-3.07)$ & $1.1 \times 10^{-4 a}$ \\
\hline
\end{tabular}

${ }^{\text {aP }}<0.05$. CASP1, caspase 1; CASP2, caspase 2; CASP3, caspase 3; CASP4, caspase 4; CASP5, caspase 5; CASP6, caspase 6; CASP7, caspase 7; CASP8, caspase 8; CASP9, caspase 9; CASP10, caspase 10; CASP12, caspase 12; CASP14, caspase 14; CI, confidence interval; OS, overall survival; HR, hazard ratio; Her-2, human epidermal growth factor receptor-2.

substrates, including CASPs 3, 6 or 7. CASP14, another divergent member of its family, has a short prodomain and possesses a variety of unique properties principally involved in epithelial cell differentiation, rather than apoptosis and inflammation. Overexpression of CASP14 has been detected in epithelial malignant tumors, indicating that CASP14 may be vital in carcinogenesis and cancer progression $(42,43)$. Furthermore, CASP14 has been reported to be an anti-apoptotic protein, bound with cytochrome $c$ to reduce cisplatin sensitivity in vitro. As CASPs and cytochrome $c$ have recently emerged as innovative targets for antitumor drugs, including camptothecin, adriamycin and cisplatin with aim to destabilize the mitochondrial membrane and activate procaspases, CASP14 may inhibit drug-induced DNA fragmentation and cell death associated with increased chemoresistance (44).

Within the CASP2 subfamily, CASP2 was associated with favorable OS for GC, while CASP9 was linked to poor OS. Functioning similarly to CASP10, CASP2 activates CASP3 and PARP to directly or indirectly initiate apoptosis, which is mainly regulated by the CRADD-caspase 2 cascade pathway. Possessing a similar dual-domain structure to FADD, CRADD contains an N-terminal caspase homology domain that affects CASP2, along with a carboxy-terminal death domain which interacts with receptor-interacting protein; interactions between CASP2 and CRADD are mediated by its caspase recruitment domain (45). It has been reported that trichostatin A can induce CRADD to activate CASP2-dependent apoptosis not only in GC cells, but also in prostate cancer cells by inhibiting histone deacetylase, which suggests a novel therapeutic approach for the treatment of GC $(46,47)$. In addition, the results of the present study were consistent with the report of Yoo et al (48), which revealed the deficient expression of CASPs 2, 6 and 7 in GC cells compared with normal mucosal cells of the stomach. Furthermore, CASP2 is involved in other processes, including $\mathrm{p} 53$ regulation, cell cycle regulation and the DNA damage response, as well as cholesterol and triacylglycerol homeostasis, in which this protein is regulated by SREBP-2 (49-51). Those processes relate to the exhibited increasing HR in the 5-FU-based adjuvant group in Table IV and it could provide a novel research direction.

With regards to the CASP9 pathway, the apoptosome (cytochrome $c$, Apaf 1 and procaspase 9) facilitates the oligomerization and subsequent auto-proteolysis of procaspase 9 to CASP9, leading to the activation of CASP3 and CASP7 (52). In addition, modified Bid proteins could transmit a signal via the intrinsic pathway of CASP activation to interact with procaspase 9 when low concentrations of CASP8 are insufficient to activate CASP3 (53). 
Table IV. Association between CASP gene expression and OS in patients with gastric cancer based on treatment strategy.

\begin{tabular}{|c|c|c|c|c|}
\hline CASP & Treatment & Cases & $\mathrm{HR}(95 \% \mathrm{CI})$ & P-value \\
\hline \multirow[t]{3}{*}{ CASP1 } & Surgery alone & 380 & $0.56(0.4-0.78)$ & $6.5 \times 10^{-4 a}$ \\
\hline & 5-FU-based adjuvant & 153 & $0.51(0.36-0.72)$ & $1.4 \times 10^{-4 a}$ \\
\hline & Other adjuvant & 76 & $0.41(0.17-1)$ & $4.2 \times 10^{-2 \mathrm{a}}$ \\
\hline \multirow{3}{*}{ CASP2 } & Surgery alone & 380 & $0.68(0.51-0.91)$ & $9.3 \times 10^{-3 a}$ \\
\hline & 5-FU-based adjuvant & 34 & $3.42(1.2-9.77)$ & $1.5 \times 10^{-2 a}$ \\
\hline & Other adjuvant & 76 & $2.59(1.07-6.25)$ & $2.8 \times 10^{-2 a}$ \\
\hline \multirow[t]{3}{*}{ CASP3 } & Surgery alone & 380 & $0.66(0.48-0.91)$ & $1.1 \times 10^{-2 a}$ \\
\hline & 5-FU-based adjuvant & 153 & $1.25(0.88-1.77)$ & $2.0 \times 10^{-1}$ \\
\hline & Other adjuvant & 76 & $0.35(0.12-1.05)$ & $5.0 \times 10^{-2}$ \\
\hline \multirow[t]{3}{*}{ CASP4 } & Surgery alone & 380 & $0.65(0.46-0.92)$ & $1.4 \times 10^{-2 a}$ \\
\hline & 5-FU-based adjuvant & 153 & $1.51(1.04-2.2)$ & $3.1 \times 10^{-2 a}$ \\
\hline & Other adjuvant & 76 & $0.52(0.2-1.36)$ & $1.7 \times 10^{-1}$ \\
\hline \multirow[t]{3}{*}{ CASP5 } & Surgery alone & 380 & $0.6(0.45-0.8)$ & $4.7 \times 10^{-4 a}$ \\
\hline & 5-FU-based adjuvant & 153 & $1.67(1.16-2.4)$ & $5.2 \times 10^{-3 a}$ \\
\hline & Other adjuvant & 76 & $0.39(0.16-0.95)$ & $3.1 \times 10^{-2 a}$ \\
\hline \multirow[t]{3}{*}{ CASP6 } & Surgery alone & 380 & $0.75(0.55-1.02)$ & $6.5 \times 10^{-2}$ \\
\hline & 5-FU-based adjuvant & 153 & $1.25(0.87-1.78)$ & $2.3 \times 10^{-1}$ \\
\hline & Other adjuvant & 76 & $0.34(0.14-0.84)$ & $1.4 \times 10^{-2 a}$ \\
\hline \multirow[t]{3}{*}{ CASP7 } & Surgery alone & 380 & $0.42(0.3-0.58)$ & $5.2 \times 10^{-8 \mathrm{a}}$ \\
\hline & 5-FU-based adjuvant & 153 & $1.28(0.86-1.92)$ & $2.3 \times 10^{-1}$ \\
\hline & Other adjuvant & 76 & $0.26(0.1-0.67)$ & $2.9 \times 10^{-3 a}$ \\
\hline \multirow{3}{*}{ CASP8 } & Surgery alone & 380 & $0.81(0.6-1.09)$ & $1.6 \times 10^{-1}$ \\
\hline & 5-FU-based adjuvant & 153 & $1.27(0.9-1.8)$ & $1.8 \times 10^{-1}$ \\
\hline & Other adjuvant & 76 & $0.31(0.13-0.75)$ & $5.8 \times 10^{-3 a}$ \\
\hline \multirow[t]{3}{*}{ CASP9 } & Surgery alone & 380 & $0.81(0.58-1.14)$ & $2.2 \times 10^{-1}$ \\
\hline & 5-FU-based adjuvant & 153 & $1.52(1.07-2.16)$ & $1.9 \times 10^{-2 \mathrm{a}}$ \\
\hline & Other adjuvant & 76 & $4.03(1.66-9.78)$ & $8.6 \times 10^{-4 a}$ \\
\hline \multirow[t]{3}{*}{ CASP10 } & Surgery alone & 380 & $1.27(0.94-1.71)$ & $1.3 \times 10^{-1}$ \\
\hline & 5-FU-based adjuvant & 153 & $1.34(0.94-1.91)$ & $1.1 \times 10^{-1}$ \\
\hline & Other adjuvant & 76 & $0.58(0.24-1.41)$ & $2.2 \times 10^{-1}$ \\
\hline \multirow[t]{3}{*}{ CASP12 } & Surgery alone & 380 & $1.55(1.15-2.08)$ & $3.7 \times 10^{-3 a}$ \\
\hline & 5-FU-based adjuvant & 34 & $1.71(0.56-5.2)$ & $3.4 \times 10^{-1}$ \\
\hline & Other adjuvant & 76 & $3.52(1.17-10.55)$ & $1.7 \times 10^{-2 a}$ \\
\hline \multirow[t]{3}{*}{ CASP14 } & Surgery alone & 380 & $1.34(0.97-1.84)$ & $7.5 \times 10^{-2}$ \\
\hline & 5-FU-based adjuvant & 34 & $2.25(0.65-7.78)$ & $1.9 \times 10^{-1}$ \\
\hline & Other adjuvant & 76 & $0.46(0.19-1.12)$ & $7.8 \times 10^{-2}$ \\
\hline
\end{tabular}

${ }^{\mathrm{a}}<$ 0.05. 5-FU, 5-Fluorouracil CASP1, caspase 1; CASP2, caspase 2; CASP3, caspase 3; CASP4, caspase 4; CASP5, caspase 5; CASP6, caspase 6; CASP7, caspase 7; CASP8, caspase 8; CASP9, caspase 9; CASP10, caspase 10; CASP12, caspase 12; CASP14, caspase 14; CI, confidence interval; OS, overall survival; HR, hazards ratio.

Overexpression of phosphorylated CASP9 (p-CASP9), an anti-apoptotic protein, in malignant GC cells could be an inhibitory mechanism of apoptosis mediated by CASP9, suggesting the protumorigenic role of CASP9 in the development of GC (54). This report of apoptosis resistance supports the findings of the present study. Numerous studies have proposed that the clearance of GC cells could be conducted by activating CASP9-induced apoptosis $(55,56)$, which may be linked to the favorable OS of patients with diffuse type GC observed in the present study. In light of these previous studies, the mechanism of CASP9 in apoptosis may involve the antagonism between p-CASP9 and CASP9, in which CASP9 is phosphorylated at Thr125, mediated by the mitogen-activated protein kinase pathway.

The Lauren classification is one of the most widely applicable classification systems in GC. It was adopted in the present study for its high repeatability and convenience in clinic, especially for its value for prognostic analysis $(57,58)$, whereas previous studies merely observed the specific relation between CASP expression and the Lauren classification, which provides a new study direction to investigate its mechanism. 
Table V. Association between CASP gene expression and OS in patients with gastric cancer patients based on sex.

\begin{tabular}{|c|c|c|c|c|}
\hline CASPs & Sex & $\mathrm{N}$ & HR (95\% CI) & $\mathrm{P}$-value \\
\hline \multirow[t]{2}{*}{ CASP1 } & Male & 545 & $0.54(0.44-0.67)$ & $1.6 \times 10^{-8 a}$ \\
\hline & Female & 236 & $0.39(0.27-0.56)$ & $1.3 \times 10^{-7 a}$ \\
\hline \multirow[t]{2}{*}{ CASP2 } & Male & 349 & $0.62(0.46-0.83)$ & $1.5 \times 10^{-3 a}$ \\
\hline & Female & 187 & $0.58(0.38-0.89)$ & $1.1 \times 10^{-2 a}$ \\
\hline \multirow[t]{2}{*}{ CASP3 } & Male & 545 & $0.47(0.37-0.6)$ & $3.4 \times 10^{-10}$ \\
\hline & Female & 236 & $0.45(0.3-0.66)$ & $3.1 \times 10^{-5 a}$ \\
\hline \multirow[t]{2}{*}{ CASP4 } & Male & 545 & $0.6(0.46-0.78)$ & $1.6 \times 10^{-4 a}$ \\
\hline & Female & 236 & $0.66(0.46-0.95)$ & $2.5 \times 10^{-3 a}$ \\
\hline \multirow[t]{2}{*}{ CASP5 } & Male & 545 & $0.69(0.56-0.85)$ & $5.8 \times 10^{-4 a}$ \\
\hline & Female & 236 & $0.53(0.37-0.77)$ & $7.7 \times 10^{-4 a}$ \\
\hline \multirow[t]{2}{*}{ CASP6 } & Male & 545 & $0.67(0.54-0.84)$ & $2.9 \times 10^{-4 a}$ \\
\hline & Female & 236 & $0.55(0.35-0.84)$ & $5.2 \times 10^{-3 a}$ \\
\hline \multirow[t]{2}{*}{ CASP7 } & Male & 545 & $0.4(0.3-0.53)$ & $1.6 \times 10^{-11}$ \\
\hline & Female & 236 & $0.32(0.21-0.49)$ & $2.5 \times 10^{-8 a}$ \\
\hline \multirow[t]{2}{*}{ CASP8 } & Male & 545 & $0.57(0.46-0.71)$ & $1.7 \times 10^{-7 a}$ \\
\hline & Female & 236 & $0.59(0.38-0.91)$ & $1.6 \times 10^{-2 \mathrm{a}}$ \\
\hline \multirow[t]{2}{*}{ CASP9 } & Male & 545 & $1.25(0.98-1.58)$ & $7.0 \times 10^{-2}$ \\
\hline & Female & 236 & $1.29(0.88-1.88)$ & $1.9 \times 10^{-1}$ \\
\hline \multirow[t]{2}{*}{ CASP10 } & Male & 545 & $1.5(1.21-1.86)$ & $1.9 \times 10^{-4 a}$ \\
\hline & Female & 236 & $1.46(1.03-2.07)$ & $3.3 \times 10^{-2 a}$ \\
\hline \multirow[t]{2}{*}{ CASP12 } & Male & 349 & $1.72(1.28-2.33)$ & $3.3 \times 10^{-4 a}$ \\
\hline & Female & 187 & $1.43(0.93-2.19)$ & $1.0 \times 10^{-1}$ \\
\hline \multirow[t]{2}{*}{ CASP14 } & Male & 349 & $1.71(1.24-2.36)$ & $9.4 \times 10^{-4 a}$ \\
\hline & Female & 187 & $1.73(1.06-2.81)$ & $2.6 \times 10^{-2 a}$ \\
\hline
\end{tabular}

${ }^{\mathrm{a}} \mathrm{P}<0.05$. CASP1, caspase 1; CASP2, caspase 2; CASP3, caspase 3; CASP4, caspase 4; CASP5, caspase 5; CASP6, caspase 6; CASP7, caspase 7; CASP8, caspase 8; CASP9, caspase 9; CASP10, caspase 10; CASP12, caspase 12; CASP14, caspase 14; CI, confidence interval; OS, overall survival; $\mathrm{HR}$, hazards ratio.

Several limitations of the present study should be considered. Further research is required to account for the effects of treatment strategies, pathological stages, HER2 expression status, sex and differentiation degree on the prognostic value of CASPs. While certain hypotheses have been proposed based on the literature and clinical statistics; further investigation is required using animal models and performing clinical trials. For instance, the number of mixed type patients is small due to the limited data in KM plotter. Additionally, although the association between mRNA expression and prognosis was explored, analysis should be conducted at the protein level. To this end, the authors aim to validate the findings of the present study in the future, using an independent cohort and RNA sequencing.

In conclusion, in the present study the prognostic value of the mRNA expression profile of CASPs in patients with GC was assessed using the KM plotter database. Among them, overexpression of CASP1-8 at the mRNA level was linked to improved OS, whereas upregulated expression of CASPs 9, 10, 12 and 14 was associated with poor OS. The findings of the present study may provide insight into the relationship between each molecule and their role in cancer. The present study
Table VI. Association of CASP gene expression with OS in patients with gastric cancer based on differentiation degree.

\begin{tabular}{|c|c|c|c|c|}
\hline CASP & $\begin{array}{c}\text { Differentiation } \\
\text { degree }\end{array}$ & $\mathrm{N}$ & $\mathrm{HR}(95 \% \mathrm{CI})$ & P-value \\
\hline \multirow[t]{3}{*}{ CASP1 } & Poor & 165 & $0.48(0.31-0.74)$ & $<0.001^{\mathrm{a}}$ \\
\hline & Moderate & 67 & $0.64(0.33-1.23)$ & 0.180 \\
\hline & Good & 32 & $0.57(0.19-1.7)$ & 0.310 \\
\hline \multirow[t]{3}{*}{ CASP2 } & Poor & 121 & $0.72(0.44-1.18)$ & 0.190 \\
\hline & Moderate & 67 & $1.91(0.9-4.07)$ & 0.086 \\
\hline & Good & - & - & - \\
\hline \multirow[t]{3}{*}{ CASP3 } & Poor & 165 & $0.85(0.57-1.27)$ & 0.430 \\
\hline & Moderate & 67 & $0.58(0.28-1.19)$ & 0.130 \\
\hline & Good & 32 & $0.21(0.08-0.54)$ & $<0.001^{\mathrm{a}}$ \\
\hline \multirow[t]{3}{*}{ CASP4 } & Poor & 165 & $0.79(0.5-1.22)$ & 0.290 \\
\hline & Moderate & 67 & $2.08(1.05-4.1)$ & $0.031^{\mathrm{a}}$ \\
\hline & Good & 32 & $0.55(0.22-1.33)$ & 0.180 \\
\hline \multirow[t]{3}{*}{ CASP5 } & Poor & 165 & $0.65(0.41-1.04)$ & 0.069 \\
\hline & Moderate & 67 & $2.01(1.02-3.95)$ & $0.040^{\mathrm{a}}$ \\
\hline & Good & 32 & $0.47(0.17-1.3)$ & 0.140 \\
\hline \multirow[t]{3}{*}{ CASP6 } & Poor & 165 & $1.4(0.93-2.1)$ & 0.110 \\
\hline & Moderate & 67 & $0.54(0.28-1.05)$ & 0.064 \\
\hline & Good & 32 & $0.48(0.16-1.42)$ & 0.170 \\
\hline \multirow[t]{3}{*}{ CASP7 } & Poor & 165 & $0.81(0.5-1.33)$ & 0.410 \\
\hline & Moderate & 67 & $0.46(0.19-1.11)$ & 0.079 \\
\hline & Good & 32 & $0.49(0.21-1.16)$ & 0.097 \\
\hline \multirow[t]{3}{*}{ CASP8 } & Poor & 165 & $0.57(0.37-0.87)$ & $0.008^{\mathrm{a}}$ \\
\hline & Moderate & 67 & $2.19(1.05-4.57)$ & $0.032^{\mathrm{a}}$ \\
\hline & Good & 32 & $2.86(0.95-8.59)$ & 0.051 \\
\hline \multirow[t]{3}{*}{ CASP9 } & Poor & 165 & $0.83(0.55-1.23)$ & 0.350 \\
\hline & Moderate & 67 & $1.65(0.82-3.31)$ & 0.160 \\
\hline & Good & 32 & $1.67(0.65-4.32)$ & 0.280 \\
\hline \multirow[t]{3}{*}{ CASP10 } & Poor & 165 & $1.5(1-2.24)$ & $0.046^{\mathrm{a}}$ \\
\hline & Moderate & 67 & $1.7(0.71-4.08)$ & 0.230 \\
\hline & Good & 32 & $0.38(0.15-1)$ & $0.042^{\mathrm{a}}$ \\
\hline \multirow[t]{3}{*}{ CASP12 } & Poor & 121 & $0.69(0.41-1.16)$ & 0.160 \\
\hline & Moderate & 67 & $0.58(0.27-1.23)$ & 0.150 \\
\hline & Good & - & - & - \\
\hline \multirow[t]{3}{*}{ CASP14 } & Poor & 121 & $0.65(0.36-1.17)$ & 0.150 \\
\hline & Moderate & 67 & $1.61(0.84-3.08)$ & 0.150 \\
\hline & Good & - & - & - \\
\hline
\end{tabular}

${ }^{\mathrm{a}} \mathrm{P}<0.05$. Sample numbers of CASP $2(\mathrm{n}=5), 12(\mathrm{n}=5)$ and $14(\mathrm{n}=5)$ are too low for meaningful analysis of well differentiation. CASP1, caspase 1; CASP2, caspase 2; CASP3, caspase 3; CASP4, caspase 4; CASP5, caspase 5; CASP6, caspase 6; CASP7, caspase 7; CASP8, caspase 8; CASP9, caspase 9; CASP10, caspase 10; CASP12, caspase 12; CASP14, caspase 14; CI, confidence interval; OS, overall survival; HR, hazards ratio.

may serve as a basis for the development of novel therapeutic strategies using CASPs as powerful and precise prognostic predictors in GC, in which potential targeting agents may be applied for the treatment of this disease; however, further study is required. 


\section{Acknowledgements}

Not applicable.

\section{Funding}

No funding was received.

\section{Availability of data and materials}

The data of the mRNA expression levels and overall survival can be found in the online KM plotter database (http://kmplot. com/analysis/).

\section{Authors' contributions}

ZW, FN and FY designed the study. ZC and XZ obtained the data. FY, ZC, XZ and JC performed data processing and statistical analysis. ZW and FN wrote the manuscript. All authors read and approved the final manuscript.

\section{Ethics approval and consent to participate}

Not applicable.

\section{Patient consent for publication}

Not applicable.

\section{Competing interests}

The authors confirm that they have no competing interests.

\section{References}

1. Orditura M, Galizia G, Sforza V, Gambardella V, Fabozzi A, Laterza MM, Andreozzi F, Ventriglia J, Savastano B, Mabilia A, et al: Treatment of gastric cancer. World $\mathrm{J}$ Gastroenterol 20: 1635-1649, 2014.

2. Lordick $F$ and Hoffmeister A: Treatment of gastric cancer. Internist (Berl) 55: 15-16, 18-22, 2014 (In German).

3. Hassan M, Watari H, AbuAlmaaty A, Ohba Y and Sakuragi N Apoptosis and molecular targeting therapy in cancer. Biomed Res Int 2014: 150845, 2014.

4. Frejlich E, Rudno-Rudzińska J, Janiszewski K, Salomon L, Kotulski K, Pelzer O, Grzebieniak Z, Tarnawa R and Kielan W: Caspases and their role in gastric cancer. Adv Clin Exp Med 22: 593-602, 2013.

5. Crawford ED and Wells JA: Caspase substrates and cellular remodeling. Annu Rev Biochem 80: 1055-1087, 2011.

6. Chowdhury I, Tharakan B and Bhat GK: Caspases-an update. Comp Biochem Physiol B Biochem Mol Biol 151: 10-27, 2008.

7. Fan TJ, Han LH, Cong RS and Liang J: Caspase family proteases and apoptosis. Acta Biochim Biophys Sin (Shanghai) 37: 719-727, 2005.

8. Mace PD, Riedl SJ and Salvesen GS: Caspase enzymology and activation mechanisms. Methods Enzymol 544: 161-178, 2014.

9. Boatright KM and Salvesen GS: Mechanisms of caspase activation. Curr Opin Cell Biol 15: 725-731, 2003.

10. Szász AM, Lánczky A, Nagy Á, Förster S, Hark K, Green JE, Boussioutas A, Busuttil R, Szabó A and Győrffy B: Cross-validation of survival associated biomarkers in gastric cancer using transcriptomic data of 1,065 patients. Oncotarget 7: 49322-49333, 2016

11. Lánczky A, Nagy Á, Bottai G, Munkácsy G, Szabó A, Santarpia L and Győrffy B: miRpower: A web-tool to validate survival-associated miRNAs utilizing expression data from 2178 breast cancer patients. Breast Cancer Res Treat 160: 439-446, 2016.
12. Dalma-Weiszhausz DD, Warrington J, Tanimoto EY and Miyada CG: The affymetrix GeneChip platform: An overview. Methods Enzymol 410: 3-28, 2006.

13. Du H, Song GX, Fang MZ, Shu YQ, Zhao X and Zhu LJ: A meta-analysis of caspase- $8-6526 \mathrm{~N}$ del polymorphism and digestive tract cancer risk. J Biomed Res 33: 173-180, 2019.

14. Kanehara I, Nakata B and Hirakawa K: Caspase-8 is scarcely silenced and its activity is well correlated with the anticancer effect of tumor necrosis factor-related apoptosis-inducing ligand in gastric cancer cells. Oncol Rep 14: 1249-1253, 2005.

15. Boege Y, Malehmir M, Healy ME, Bettermann K, Lorentzen A, Vucur M, Ahuja AK, Böhm F, Mertens JC, Shimizu Y, et al: A dual role of caspase- 8 in triggering and sensing proliferation-associated DNA damage, a key determinant of liver cancer development. Cancer cell 32: 342.e10-359.e10, 2017.

16. Gu Q, Wang JD, Xia HH, Lin MC, He H, Zou B, Tu SP, Yang Y Liu XG, Lam SK, et al: Activation of the caspase-8/Bid and Bax pathways in aspirin-induced apoptosis in gastric cancer. Carcinogenesis 26: 541-546, 2005.

17. Li Y, Wu K and Yu WP: The expression and activity of caspase- 8 in the process of vitamin $\mathrm{E}$ succinate-induced apoptosis in human gastric carcinoma SGC-7901 cells. Zhonghua Yu Fang Yi Xue Za Zhi 37: 112-114, 2003 (In Chinese).

18. Mondal A and Bennett LL: Resveratrol enhances the efficacy of sorafenib mediated apoptosis in human breast cancer MCF7 cells through ROS, cell cycle inhibition, caspase 3 and PARP cleavage. Biomed Pharmacother 84: 1906-1914, 2016.

19. Mantena SK, Sharma SD and Katiyar SK: Berberine inhibits growth, induces G1 arrest and apoptosis in human epidermoid carcinoma A431 cells by regulating Cdki-Cdk-cyclin cascade, disruption of mitochondrial membrane potential and cleavage of caspase 3 and PARP. Carcinogenesis 27: 2018-2027, 2006.

20. Yinjun L, Jie J, Weilai X and Xiangming T: Homoharringtonine mediates myeloid cell apoptosis via upregulation of pro-apoptotic bax and inducing caspase-3-mediated cleavage of poly(ADP-ribose) polymerase (PARP). Am J Hematol 76: 199-204, 2004.

21. Tyagi A, Agarwal C, Harrison G, Glode LM and Agarwal R: Silibinin causes cell cycle arrest and apoptosis in human bladder transitional cell carcinoma cells by regulating CDKI-CDK-cyclin cascade, and caspase 3 and PARP cleavages. Carcinogenesis 25: 1711-1720, 2004.

22. Vormoor B, Schlosser YT, Blair H, Sharma A, Wilkinson S, Newell DR and Curtin N: Sensitizing Ewing sarcoma to chemoand radiotherapy by inhibition of the DNA-repair enzymes DNA protein kinase (DNA-PK) and poly-ADP-ribose polymerase (PARP) 1/2. Oncotarget 8: 113418-113430, 2017.

23. Alikarami F, Safa M, Faranoush M, Hayat P and Kazemi A: Inhibition of DNA-PK enhances chemosensitivity of B-cell precursor acute lymphoblastic leukemia cells to doxorubicin. Biomed Pharmacother 94: 1077-1093, 2017.

24. Cho HJ, Kim IK, Park SM, Baek KE, Nam IK, Park SH, Ryu KJ, Choi J, Ryu J, Hong SC, et al: VEGF-C mediates RhoGDI2-induced gastric cancer cell metastasis and cisplatin resistance. Int J Cancer 135: 1553-1563, 2014.

25. Zheng Z, He XY, Li JF, Yu BQ, Chen XH, Ji J, Zhang JN, Gu QL, Zhu ZG and Liu BY: RhoGDI2 confers resistance to 5-fluorouracil in human gastric cancer cells. Oncol Lett 5: 255-260, 2013.

26. Essmann F, Wieder T, Otto A, Müller EC, Dörken B and Daniel PT: GDP dissociation inhibitor D4-GDI (Rho-GDI 2), but not the homologous rho-GDI 1 , is cleaved by caspase- 3 during drug-induced apoptosis. Biochem J 346 Pt 3: 777-783, 2000.

27. Fiorillo M, Peiris-Pagès M, Sanchez-Alvarez R, Bartella L, Di Donna L, Dolce V, Sindona G, Sotgia F, Cappello AR and Lisanti MP: Bergamot natural products eradicate cancer stem cells (CSCs) by targeting mevalonate, Rho-GDI-signalling and mitochondrial metabolism. Biochim Biophys Acta Bioenerg 1859: 984-996, 2018.

28. Wu Z, Wu L, Weng D, Xu D, Geng J and Zhao F: Reduced expression of lamin $\mathrm{A} / \mathrm{C}$ correlates with poor histological differentiation and prognosis in primary gastric carcinoma. J Exp Clin Cancer Res 28: 8, 2009.

29. Gibot L, Follet J, Metges JP, Auvray P, Simon B, Corcos L and Le Jossic-Corcos C: Human caspase 7 is positively controlled by SREBP-1 and SREBP-2. Biochem J 420: 473-483, 2009.

30. Lamy L, Ngo VN, Emre NC, Shaffer AL III, Yang Y, Tian E, Nair V, Kruhlak MJ, Zingone A, Landgren O and Staudt LM: Control of autophagic cell death by caspase-10 in multiple myeloma. Cancer Cell 23: 435-449, 2013. 
31. Hitzler I, Sayi A, Kohler E, Engler DB, Koch KN, Hardt WD and Müller A: Caspase-1 has both proinflammatory and regulatory properties in Helicobacter infections, which are differentially mediated by its substrates IL-1 $\beta$ and IL-18. J Immunol 188: 3594-3602, 2012.

32. Yaguchi T, Saito M, Yasuda Y and Nishizaki T: Caspase-4 activation in association with decreased adenosine deaminase activity may be a factor for gastric ulcer. Digestion 81: 62-67, 2010.

33. Namiot Z, Kemona A, Stasiewicz J, Marcinkiewicz M, Namiot A and Gorski J: Adenosine deaminase activity in gastric cancer. Cancer Lett 82: 95-98, 1994.

34. Terlizzi M, Colarusso C, De Rosa I, De Rosa N, Somma P, Curcio C, Sanduzzi A, Micheli P, Molino A, Saccomanno A, et al: Circulating and tumor-associated caspase-4: A novel diagnostic and prognostic biomarker for non-small cell lung cancer. Oncotarget 9: 19356-19367, 2018.

35. Raposo TP, Beirão BC, Pang LY, Queiroga FL and Argyle DJ: Inflammation and cancer: Till death tears them apart. Vet J 205 161-174, 2015.

36. Viganò E, Diamond CE, Spreafico R, Balachander A, Sobota RM and Mortellaro A: Human caspase-4 and caspase-5 regulate the one-step non-canonical inflammasome activation in monocytes. Nat Commun 6: 8761, 2015.

37. Williams TM, Leeth RA, Rothschild DE, McDaniel DK, Coutermarsh-Ott SL, Simmons AE, Kable KH, Heid B and Allen IC: Caspase-11 attenuates gastrointestinal inflammation and experimental colitis pathogenesis. Am J Physiol Gastrointest Liver Physiol 308: G139-G150, 2015.

38. Rao RV, Ellerby HM and Bredesen DE: Coupling endoplasmic reticulum stress to the cell death program. Cell Death Differ 11: 372-380, 2004

39. Nakagawa T and Yuan J: Cross-talk between two cysteine protease families. Activation of caspase-12 by calpain in apoptosis. J Cell Biol 150: 887-894, 2000.

40. Saleh M, Vaillancourt JP, Graham RK, Huyck M, Srinivasula SM, Alnemri ES, Steinberg MH, Nolan V, Baldwin CT, Hotchkiss RS, et al: Differential modulation of endotoxin responsiveness by human caspase-12 polymorphisms. Nature 429: 75-79, 2004

41. Van de Craen M, Van Loo G, Pype S, Van Criekinge W, Van den brande I, Molemans F, Fiers W, Declercq W and Vandenabeele P. Identification of a new caspase homologue: Caspase-14. Cell Death Differ 5: 838-846, 1998.

42. Koenig U, Sommergruber W and Lippens S: Aberrant expression of caspase-14 in epithelial tumors. Biochem Biophys Res Commun 335: 309-313, 2005.

43. Krajewska M, Kim H, Shin E, Kennedy S, Duffy MJ, Wong YF, Marr D, Mikolajczyk J, Shabaik A, Meinhold-Heerlein I, et al: Tumor-associated alterations in caspase-14 expression in epithelial malignancies. Clin Cancer Res 11: 5462-5471, 2005.

44. Fang HY, Chen CY, Hung MF, Hsiao YT, Chiang TC, Lin TY, Chang HW, Chow KC and Ko WJ: Caspase-14 is an anti-apoptotic protein targeting apoptosis-inducing factor in lung adenocarcinomas. Oncol Rep 26: 359-369, 2011.

45. Ahmad M, Srinivasula SM, Wang L, Talanian RV, Litwack G, Fernandes-Alnemri T and Alnemri ES: CRADD, a novel human apoptotic adaptor molecule for caspase-2, and FasL/tumor necrosis factor receptor-interacting protein RIP. Cancer Res 57: 615-619, 1997.
46. Shen Q, Tang W, Sun J, Feng L, Jin H and Wang X: Regulation of CRADD-caspase 2 cascade by histone deacetylase 1 in gastric cancer. Am J Transl Res 6: 538-547, 2014.

47. Taghiyev AF, Guseva NV, Glover RA, Rokhlin OW and Cohen MB: TSA-induced cell death in prostate cancer cell lines is caspase-2 dependent and involves the PIDDosome. Cancer Biol Ther 5: 1199-1205, 2006.

48. Yoo NJ, Lee JW, Kim YJ, Soung YH, Kim SY, Nam SW, Park WS, Lee JY and Lee SH: Loss of caspase-2, -6 and -7 expression in gastric cancers. APMIS 112: 330-335, 2004.

49. Mandruzzato S, Brasseur F, Andry G, Boon T and van der Bruggen P: A CASP-8 mutation recognized by cytolytic $T$ lymphocytes on a human head and neck carcinoma. J Exp Med 186: 785-793, 1997.

50. Nicholson DW: Caspase structure, proteolytic substrates, and function during apoptotic cell death. Cell Death Differ 6: 1028-1042, 1999.

51. Logette E, Le Jossic-Corcos C, Masson D, Solier S, Sequeira-Legrand A, Dugail I, Lemaire-Ewing S, Desoche L, Solary E and Corcos L: Caspase-2, a novel lipid sensor under the control of sterol regulatory element binding protein 2. Mol Cell Biol 25: 9621-9631, 2005.

52. Acehan D, Jiang X, Morgan DG, Heuser JE, Wang X and Akey CW: Three-dimensional structure of the apoptosome: Implications for assembly, procaspase- 9 binding, and activation. Mol Cell 9: 423-432, 2002.

53. Kluck RM, Bossy-Wetzel E, Green DR and Newmeyer DD: The release of cytochrome $\mathrm{c}$ from mitochondria: A primary site for $\mathrm{Bcl}-2$ regulation of apoptosis. Science 275: 1132-1136, 1997.

54. Yoo NJ, Lee SH, Jeong EG and Lee SH: Expression of phosphorylated caspase-9 in gastric carcinomas. APMIS 115: 354-359, 2007.

55. Wang H, Li H, Chen F, Luo J, Gu J, Wang H, Wu H and $\mathrm{Xu}$ Y: Baicalin extracted from Huangqin (Radix Scutellariae Baicalensis) induces apoptosis in gastric cancer cells by regulating B cell lymphoma (Bcl-2)/Bcl-2-associated $\mathrm{X}$ protein and activating caspase-3 and caspase-9. J Tradit Chin Med 37: 229-5, 2017.

56. Chang-Qing F, Yi L, De-Guang W, Qing-Bin S, Xiang-Min H, $\mathrm{Na} T$ and Jian-Hua L: Immune clearance gastric carcinoma cells in ascites by activating caspase-9-induced apoptosis. APMIS 119: 173-179, 2011.

57. Chen YC, Fang WL, Wang RF, Liu CA, Yang MH, Lo SS, Wu CW, Li AF, Shyr YM and Huang KH: Clinicopathological variation of lauren classification in gastric cancer. Pathol Oncol Res 22: 197-202, 2016.

58. Ma J, Shen H, Kapesa L and Zeng S: Lauren classification and individualized chemotherapy in gastric cancer. Oncol Lett 11: 2959-2964, 2016

This work is licensed under a Creative Commons Attribution-NonCommercial-NoDerivatives 4.0 International (CC BY-NC-ND 4.0) License. 